\title{
OCUPACIONES ARCAICAS Y PROBABLES EVIDENCIAS DE NAVEGACIÓN TEMPRANA EN LA COSTA ARREICA DE ANTOFAGASTA, CHILE
}

\author{
ARCHAIC OCCUPATIONS AND PROBABLE EVIDENCE OF EARLY NAVIGATION \\ IN THE ARHEIC COAST OF ANTOFAGASTA
}

\author{
Victoria Castro ${ }^{1,2}$, Carlos Aldunate ${ }^{3}$, Varinia Varela ${ }^{3}$, Laura Olguín 4 , Pedro Andrade ${ }^{5}$, \\ Francisco García-Albarido 6 , Felipe Rubio ${ }^{7}$, Pilar Castro ${ }^{8}$, Antonio Maldonado ${ }^{9,} 10$ y Jimena Ruz ${ }^{11}$
}

\begin{abstract}
El estudio intensivo del sitio Copaca 1, al sur de Tocopilla, proporciona antecedentes que permiten profundizar el conocimiento sobre el período Arcaico en la costa arreica de Antofagasta, para una sociedad que vivió de una eficiente adaptación costera, sin recursos complementarios extralocales. Estos nuevos hallazgos enriquecen la secuencia cronológica del Holoceno Medio, sus sistemas de asentamientos, prácticas mortuorias, modos de vida y probables evidencias de navegación.
\end{abstract}

Palabras claves: costa arreica, período Arcaico, asentamientos, cronología, funebria.

The intensive archaeological and biological study of a singular site (Copaca 1) in the arheic coast of Antofagasta, Chile, brings new data that contributes to a deeper understanding of the Middle Archaic Period, its settlement patterns, its funerary practices, and its ways of life. It also provides probable evidence of early navigation.

Key words: Arheic coast, Archaic Period, funerary practices.

\section{Antecedentes}

La costa de Antofagasta está dominada por la acción permanente del anticiclón subtropical del Pacífico Sur, con un clima desértico que se caracteriza por bancos de niebla generosos llamados camanchaca, atrapados por una abrupta cordillera, que permiten la existencia de una escasa flora en la que destacan cactáceas y una fauna asociada que comprenden guanacos, zorros, roedores, reptiles y aves. Al sur de la desembocadura del río Loa, se presenta una costa de arreísmo absoluto, donde la vida solo es posible gracias a algunas aguadas. No obstante, el ser humano ha transitado y ocupado estas tierras desde milenios, gracias a la generosidad del mar Pacífico.

Llagostera (2005) ofrece una secuencia de la ocupación arcaica de esta zona donde destaca la Fase I (10.700 a 9.500 a.p. $)^{1}$, en que poblaciones pescadoras, que manejaban una tecnología específica y eficiente ${ }^{2}$, consumieron básicamente peces y mariscos de las mismas especies que existen en la actualidad, así como mamíferos marinos, camélidos, cánidos, roedores y aves en baja proporción. La Fase II (9.500 a 9.000 a.p.), está caracterizada fundamentalmente por la presencia de litos geométricos, objetos confeccionados básicamente en arenisca, de gruesas formas discoidales y poligonales que no parecen

\footnotetext{
1 Departamento de Antropología, Facultad de Ciencias Sociales, Universidad Alberto Hurtado, Santiago, Chile. macastrr@uahurtado.cl

2 Universidad de Chile, Departamento de Antropología, Santiago, Chile.

3 Museo Chileno de Arte Precolombino, Bandera 361, Santiago, Santiago. caldunate@museoprecolombino.cl; vvarela@museoprecolombino.cl

4 Programa de Doctorado, Universidad Católica del Norte, San Pedro de Atacama, Chile. olguinlaura.o@gmail.com

5 Universidad de Concepción, Concepción, Chile, nuevocelular2@yahoo.com.mx

6620 W Mulberry St., Fort Collins, Colorado, EE.UU. 80521. fcogag2@ hotmail.com

7 felipe_hkd@hotmail.com

$8 \quad$ Código postal 8330091, Chile. pilar2383@gmail.com

9 CEAZA, Centro de Estudios Avanzados en Zonas Áridas, Universidad de La Serena, La Serena, Chile. amaldona@userena.cl

10 Departamento de Biología Marina, Universidad Católica del Norte, Coquimbo, Chile.

11 Pasaje San Francisco de Asís 1340, Villa Santa Beatriz, Curacaví, Chile. morgana.jr@gmail.com
} 
tener un uso en la obtención directa de recursos. Las especies ictiológicas capturadas continúan en igual variedad y tamaño que en la ocupación anterior reflejando que no hubo grandes cambios en las taxonomías ni en el equipo tecnológico.

En la costa de Antofagasta no habría evidencias arqueológicas documentadas para la Fase III ( 9.000 a 6.000 a.p.). En recientes investigaciones en la localidad de Taltal, en el extremo meridional de esta franja de arreísmo, se han obtenido fechados absolutos de 8250/8600 a.C., para la explotación de una mina de óxido de hierro en la quebrada de San Ramón, asociada a martillos líticos, lascas y restos malacológicos (Salazar et al. 2009). Llagostera (2005) divide su Fase IV (6.000 a 5.000 a.p.), en dos Subfases: la Temprana, caracterizada por el anzuelo de concha circular y la Tardía por el anzuelo de concha con vástago recto ${ }^{3}$. En su opinión, en la Fase V (5.000 a 4.000 a.p.) desaparece el anzuelo de concha y se reemplaza por el de espina de cactus $^{4}$. Es característico de este momento el sitio Caleta Huelén 42 (CH42), en desembocadura del río Loa, el extremo septentrional de la zona arreica (Núñez et al. 1974), donde distintos grados de sedentarismo fueron posibles gracias a esta vía fluvial (cfr. Schaedel 1957). La Fase VI (4.000 a 3.000 a.p.), muestra rasgos transicionales en la forma y materias primas de los anzuelos. A las estructuras habitacionales y/o mortuorias más tardías de CH42, que se integran a esta fase, se les agregan pisos selladores de argamasa de ceniza de algas que cubren restos humanos, agregando una funcionalidad funeraria a los sitios habitacionales, lo que también se advierte en los sitios de Cobija y Punta Guasilla (Bittmann 1984)5.

Durante las últimas fases del Arcaico Tardío las poblaciones de tierras altas del Salar de Atacama, desarrollaron desplazamientos de corto y largo aliento, posiblemente alcanzando el litoral marino, ya que en los registros de Tulán 52, Tulán 54 y Tulán 109, en la cuenca del Salar de Atacama, es posible encontrar restos malacológicos de Oliva peruviana, Pecten purpuratus y Choromytilus sp., junto con huesos de camélidos domésticos, que invitan a pensar en la movilidad necesaria para alcanzar la costa, que pudo facilitarse con animales dispuestos para la carga durante la fase Tilocalar, ca. 3080 a 2380 a.p. (Núñez et al. 2008). Con estos ejemplos denotamos la importancia que tuvo para la gente de esta época, la diversificación de recursos. Si bien durante el largo período Arcaico en la costa arreica de Antofagasta no existieron prácticas funerarias tan complejas como Chinchorro, comparten con ellas un uso extensivo de los pigmentos rojos de óxidos de hierro. De ello da cuenta la mencionada extracción tan temprana de ese material, la enorme cantidad de piedras para moler el pigmento y el uso del mismo como sello en las sepulturas y para empolvar los cuerpos de los difuntos, práctica que continuará durante el período siguiente. Los nuevos registros obtenidos en Copaca, enriquecen y diversifican los antecedentes ofrecidos.

\section{Material y Método}

\section{El sitio Copaca 1 y su estratigrafía}

El sitio Copaca $1\left(22^{\circ} 20^{\prime} \mathrm{S} ; 70^{\circ} 14^{\prime} \mathrm{W}\right)$ está localizado en el litoral árido de arreísmo absoluto del norte de Chile, entre Antofagasta y Tocopilla ${ }^{6}$ (Figura 1). Se encuentra emplazado a cielo abierto en la segunda terraza de erosión marina a $22 \mathrm{msm}$, adyacente y de fácil acceso al borde del litoral actual, a una distancia de $100 \mathrm{~m}$ del mar. Corresponde a un extenso conchal de $5.000 \mathrm{~m}^{2}$ (Figura 2), con una potente densidad estratigráfica de 2,5 $\mathrm{m}$ de profundidad que comprende una secuencia ocupacional de grupos cazadores, recolectores y pescadores del Holoceno Medio, quienes ocuparon el sitio por más de 3.000 años como un campamento multifuncional y semipermanente. Su estratigrafía muestra al menos nueve eventos ocupacionales y los contextos fechados abarcan desde $4540 \pm 25$ a.p. a $7010 \pm 25$ a.p. (Tabla 1 ).

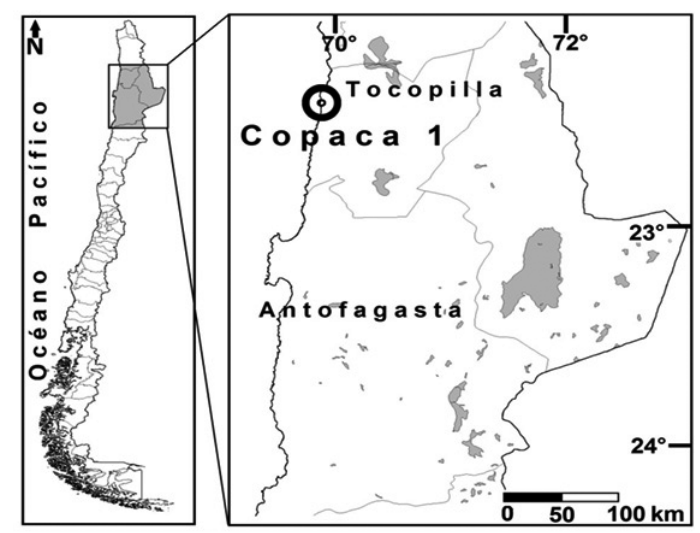

Figura 1. Localización del sitio Copaca 1 (tomada de Andrade et al. 2016).

Geographical location of Copaca 1 (taken from Andrade et al. 2016). 


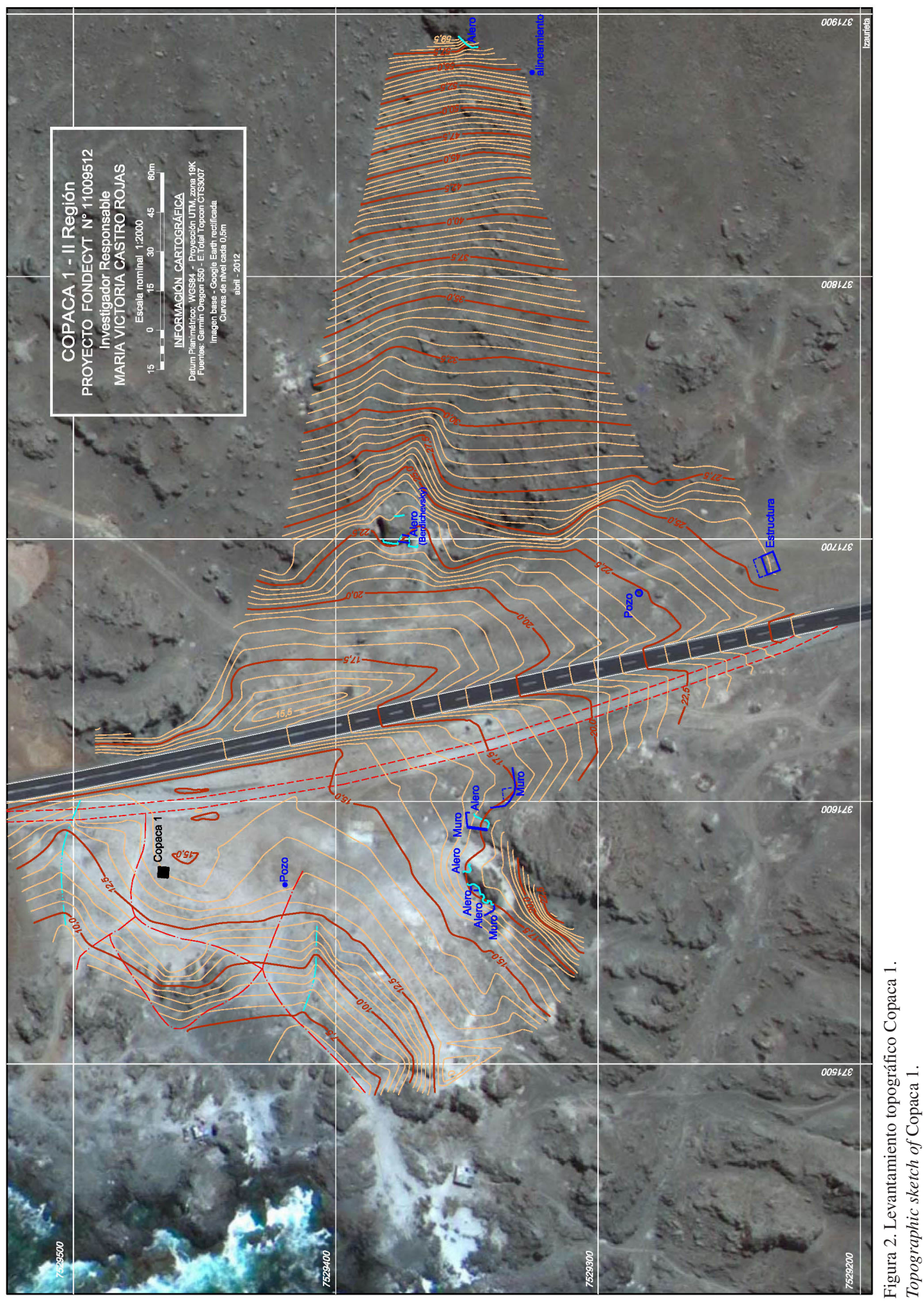




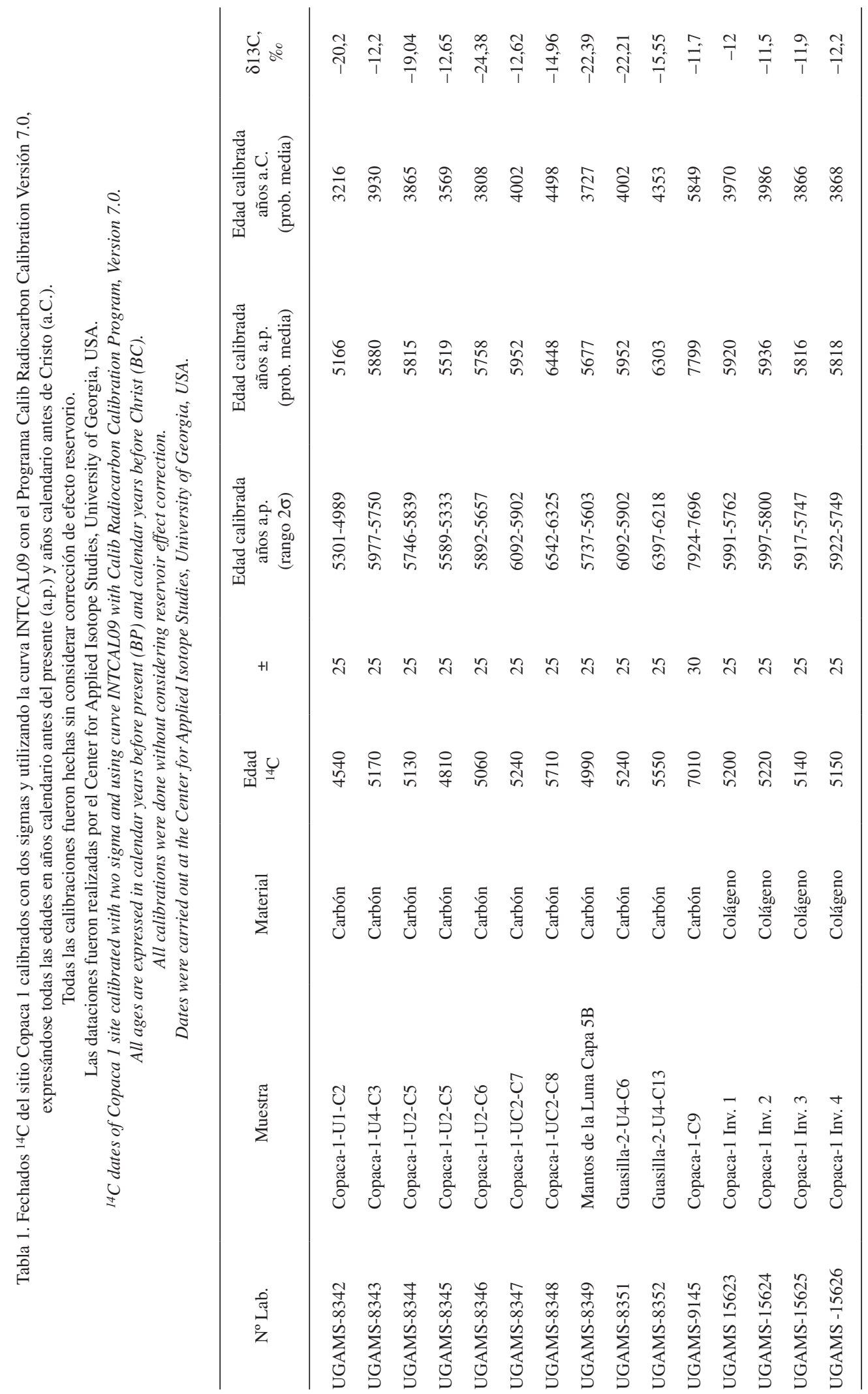




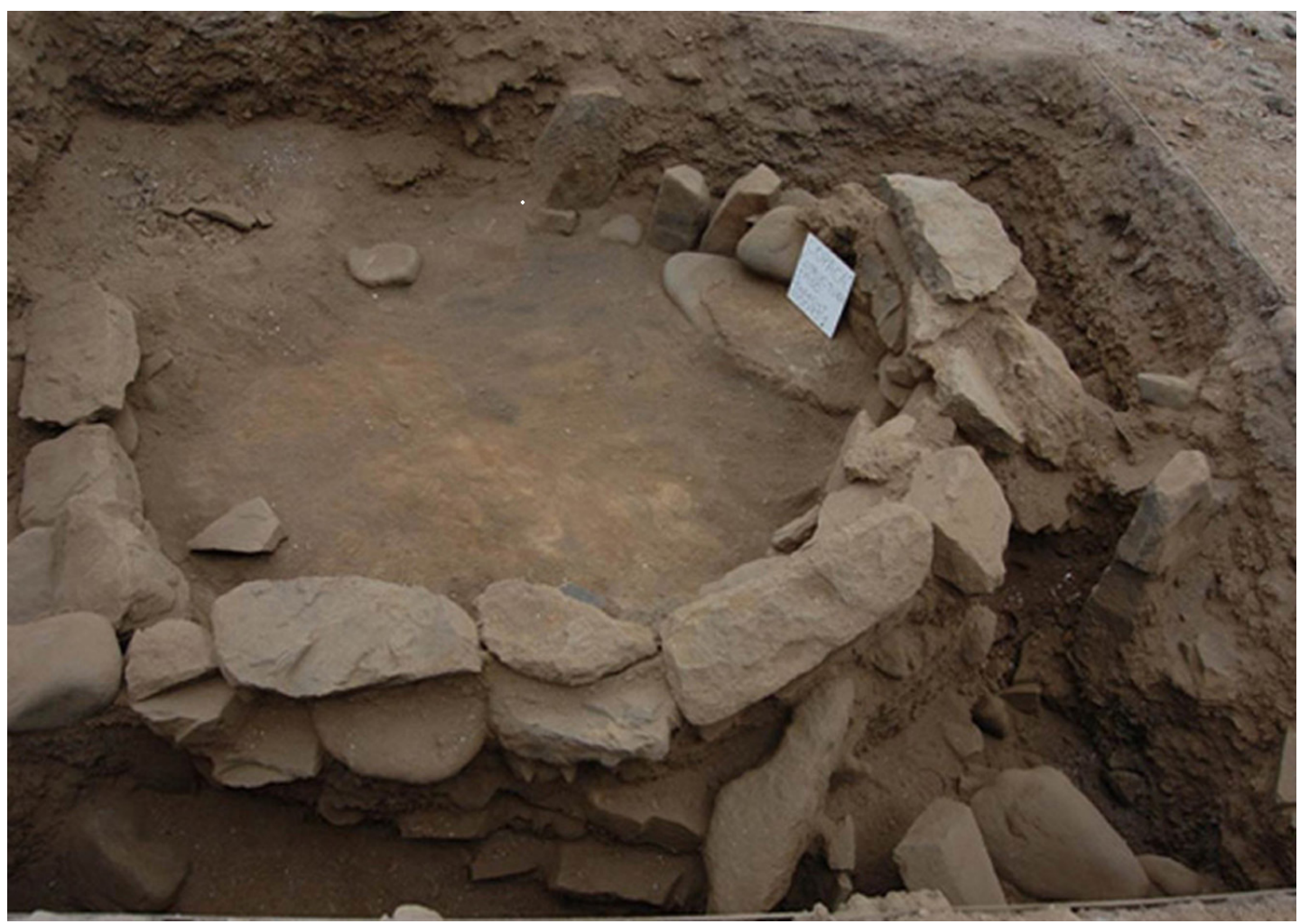

Figura 3. Estructura de piedra en Copaca 1. Stone structure at Copaca 1.

El sitio está formado por una gran acumulación de restos de la actividad de desconche de moluscos, procesamiento y consumo de fauna marina y terrestre, así como por evidencias del procesamiento, uso y descarte de instrumentos líticos, óseos y conquiológicos. Destacan las capas 5 y 6 donde el sitio fue utilizado como repositorio funerario asociado a arquitectura en piedra (Figura 3). La fauna marina está constituida por lobos marinos, delfines, cetáceos, invertebrados marinos, peces y aves, mientras que la fauna terrestre está representada por camélidos y un roedor. El instrumental para la captura y procesamiento de estos recursos incluye puntas de proyectil, barbas y cuerpos de arpón, poteras, pesas, anzuelos, raederas y cuchillos, entre otros.

Para el estudio del sitio se realizaron ocho cuadrículas adyacentes y desplegadas en una gran unidad de $96 \mathrm{~m}^{2}$. Se excavó por capas naturales, se realizaron dos columnas de control, una de arqueofauna $(0,5 \times 0,5 \mathrm{~m})$ y otra de arquebotánica $(0,2 \times 0,2 \mathrm{~m})$, para ser procesadas en laboratorio.

\section{Resultados}

\section{Funebria y asociaciones}

La excavación del sitio reveló la presencia de cuatro individuos, registrados en las capas 5 y 6 , fechadas en $4.810 \pm 25$ a.p. (UGAM 8345) y $5.060 \pm 25$ a.p. (UGAM 8346), respectivamente. Las inhumaciones estaban dispuestas en una estructura subcircular de piedras de tipología similar a aquellas de CH42 (Núñez 1971; Zlatar 1983). Sobre la estructura y los cuerpos, se depositaron bloques de piedra, sin orden aparente, fragmentos de erizos, concha de loco, una lapa de gran tamaño. El entierro principal, individuo 1 (masculino, entre 35 y 45 años de edad, altura promedio de $160,27 \pm 1,7 \mathrm{~cm}$ ) (Andrade et al. 2016), depositado sobre un piso preparado especialmente con limo fino de color ocre y su cráneo estaba rodeado de piedras. Fue puesto en posición decúbito dorsal extendido (articulado casi en su totalidad), con las extremidades inferiores separadas y manos 
y brazos abiertos (Figura 4a). En los extremos de cada mano fue dispuesta una piedra plana de tamaño mediano con pintura roja. Se observaron alteraciones en el área de las costillas, ambas cinturas escapulares y en las vértebras cervicales que fueron desplazadas (pero mantenían su relación anatómica), introduciendo entre la primera y segunda vértebra (esta última con evidencias de haber estado expuesta al fuego) dos conchas completas de erizos (Figura 4b). Sobre el cuerpo se espolvoreó óxido de hierro, que impregnó sus huesos. Asociado a la pelvis se encontraron conchas de erizos quebradas. A la altura de la pelvis y entre las piernas de este cuerpo, se encontraron los restos óseos de un infante, individuo 4 (sexo indeterminado, de unos 3 a 5 años de edad) (Loyola y Rebeco 2011) con una concha de lapa (Fisurella costata) sobre su pelvis. Este cuerpo se encontraba desarticulado, sin todas sus unidades óseas. Como ofrenda, adyacente al cuerpo del infante, había un guijarro con pigmento rojo y un hueso del cráneo de un pescado, posiblemente corvinilla (Sciaena deliciosa). Además se rescataron: un pequeño pulidor lítico, dos anzuelos de Choromytilus chorus de vástago recto, un fragmento de pesa del mismo material, punzones de huesos de camélido y huesos de marlín (Teyttapturus audax).
En la capa 6, bajo el sello de limo e inmediatamente bajo los individuos 1 y 4 , se registraron otros dos entierros, claramente secundarios (individuos 2 y 3 ) cuyas extremidades inferiores se encontraron depositadas como un "paquete" ordenado junto a sus respectivos cráneos. Ellos también se asociaron a huesos de camélidos, xiphidos, moluscos (lapas, chitones, tégulas), junto con una barba de hueso. El individuo 2 (masculino, entre 25 a 30 años de edad, estatura promedio 165,20 $\pm 3,26 \mathrm{~cm}$ ) (Andrade et al. 2015) a cada lado de su cráneo, tuvo una lasca lítica, un artefacto que pudo ser el mango de madera de un arpón y dos barbas de arpón, confeccionadas en hueso de camélido. Debajo de uno de los cráneos, pero asociados a ambos entierros, se dispusieron cuatro "espadas" de xiphidos (albacora o marlín). Finalmente junto al individuo 3 (femenino, entre 20 y 25 años de edad, estatura promedio de 152,03 $\pm 2,70$ $\mathrm{cm}$ ) (Andrade et al. 2015) se encontró un ofertorio abundante: un punzón óseo fracturado de camélido, un fragmento de vástago o astil de madera, y partes de una potera de hueso. Asociados al cráneo, una bipunta de calcedonia, un anzuelo de hueso y una barba de anzuelo compuesto del mismo material. $\mathrm{Al}$ encontrar falanges sueltas de sus dedos, se comprobó que estaban teñidas de ocre.
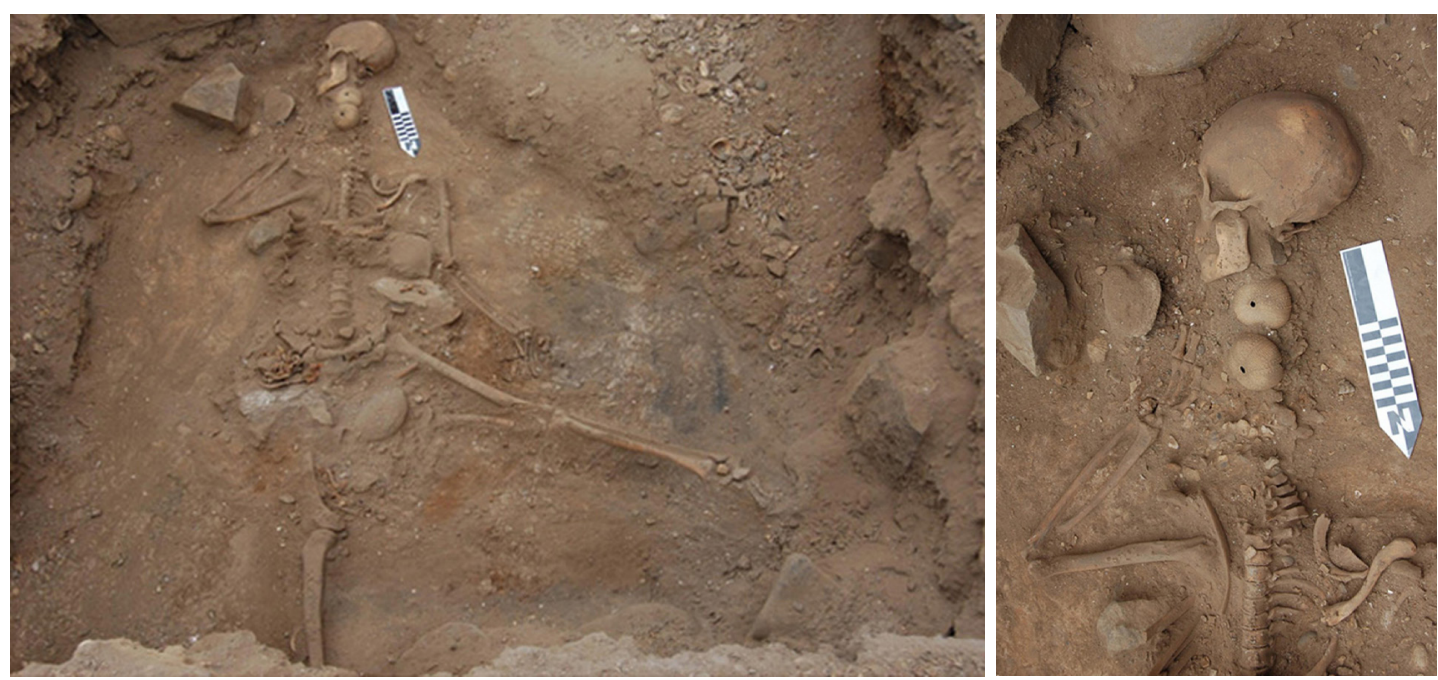

Figura 4. (a). Individuo 1 en posición extendida decúbito dorsal, con las extremidades inferiores separadas y el cráneo desplazado (tomada de Andrade et al. 2016), (b). Detalle del cuello, Individuo 1, con reemplazo de vértebras cervicales por dos conchas de erizos (tomada de Andrade et al. 2016).

(a) Individual 1 in supine position, with lower limbs separated, and displaced cranium (taken from Andrade et al. 2016), (b) detail of the neck, Individual 1, with cervical vertebrae replaced with two sea urchin shells (taken from Andrade et al. 2016). 
Los análisis de isotopos de $\delta 15 \mathrm{~N}$ de los individuos 1, 2 y 3 mostraron altos valores, indicando una dieta básicamente marina (Andrade et al. 2016: Tabla 8; Kline et al. 2013) lo que queda confirmado por el restringido ambiente hiperárido y arreico de la localidad, que no da acceso a dependencia de recursos vegetales, ni menos agrícolas. Por otra parte, este litoral es uno de los mares más ricos del planeta y fue prácticamente el único recurso alimenticio de sus habitantes arcaicos, lo que se acredita además con los contextos exhumados del sitio.

\section{Arqueofauna}

Mamíferos terrestres y marinos. El estudio se efectuó sobre 4.320 restos óseos de mamíferos, logrando identificar taxonómicamente cerca de un $60 \%$ del total de los materiales analizados. Los resultados develaron una predominancia de mamíferos marinos que superan el $55 \%$ de la muestra (Figura 5). Cabe destacar que a lo largo de la secuencia ocupacional del sitio existe abundancia de restos de cetáceos, específicamente delfínidos, los cuales constituyen el principal grupo de mamíferos especialmente en los estratos superiores del yacimiento. No obstante, en momentos más tempranos hay predominancia de otáridos.

Se observa un buen estado de conservación de las piezas óseas, con una baja incidencia de meteorización (Beherensmeyer 1978). Asimismo, el registro de marcas de origen antrópico (Lyman 1994) mostró una frecuencia de $0,3 \%$ para las huellas de corte $(\mathrm{N}=13)$ y $4 \%$ para alteraciones térmicas $(\mathrm{N}=175)$. Las huellas de corte se observan tanto en la porción apendicular como axial en individuos correspondientes a las familias Delphinidae, Camelidae y Otariidae, que se asociarían a acciones de desmembramiento-trozamiento y/o extracción de carne. Por otra parte, la presencia de huesos con alteraciones térmicas podría asignarse más

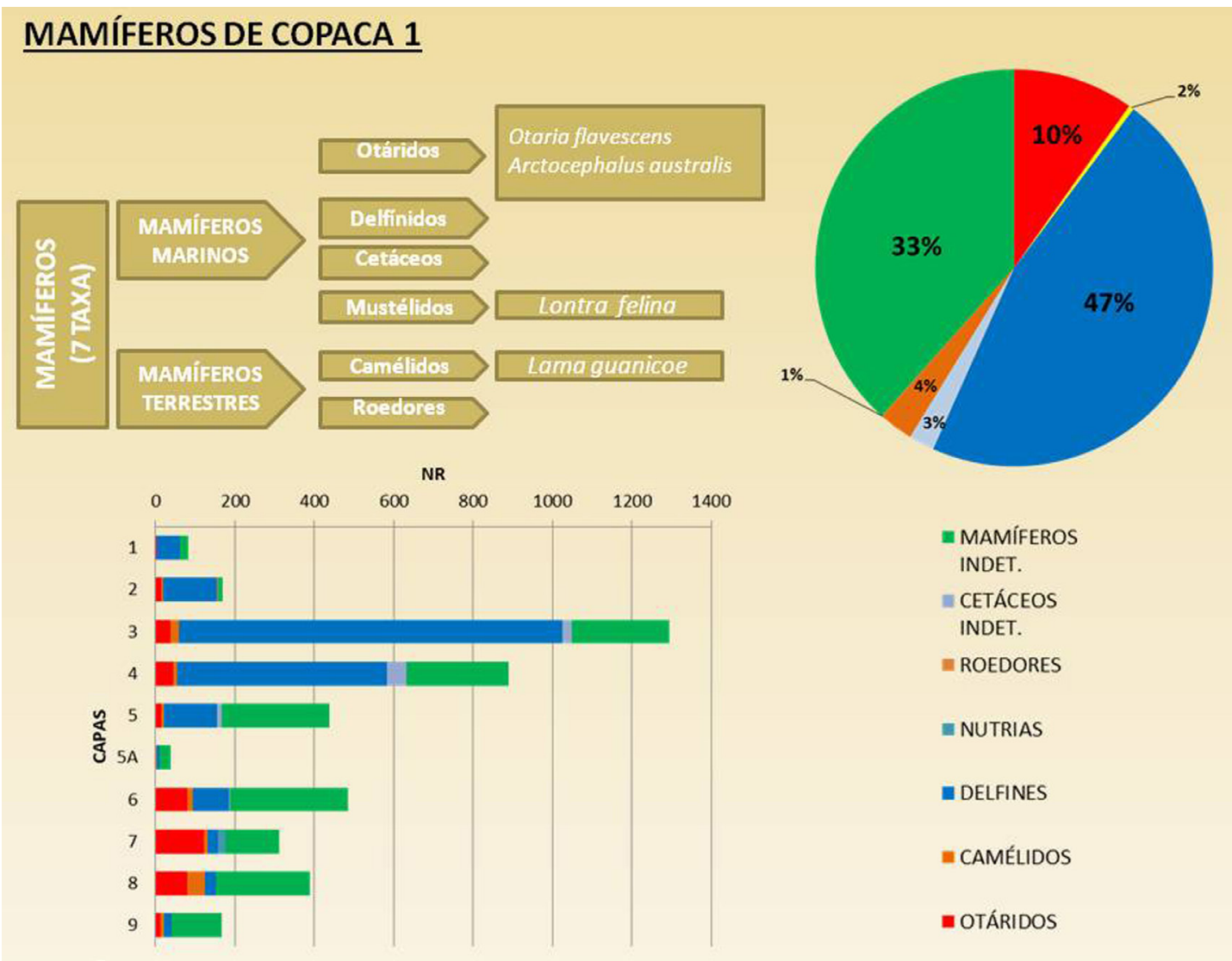

Figura 5. Mamíferos en Copaca 1.

Mammals in Copaca 1 site. 
bien a la acción de descarte de la pieza ósea sobre el lugar de cocción (fogón) más que a la acción culinaria o de cocción misma, pues el cambio en la coloración de la superficie del hueso se produce cuando este se encuentra desprovisto del tejido blando (carne).

(a) Cetáceos. A partir de la determinación anatómica de los restos fue posible identificar una copiosa presencia de cetáceos, específicamente de delfínidos (47\%), los cuales en términos taxonómicos podrían corresponder a los géneros de Cephalorhynchus y/o Tursiops, según la presencia diagnóstica del complejo óseo tímpano periótico (Carolina Gutstein, comunicación personal, 2013).

Se identificó escasa presencia de cetáceos mayores como ballenas y cachalotes, entre otros. $\mathrm{La}$ ausencia de caracteres morfológicos diagnósticos impidió adscribirlos a nivel de especie. Dichos restos se concentran en los eventos ocupacionales superiores del conchal, particularmente en las capas 2 y 3 , no obstante, también se registraron piezas óseas asociadas al contexto de inhumación de la capa 5.

(b) Otáridos. Constituyen el $10 \%$ del total de los restos de mamíferos analizados. Su distribución es homogénea a lo largo de la secuencia ocupacional, aumentando paulatinamente hacia los estratos inferiores (Capa 7 y 8). Es probable que la mayor parte de los restos correspondan a la especie Otaria flavescens (lobo marino de un pelo) (Quintana et al. 2000). Pero ante la ausencia de elementos diagnósticos se identificaron solo a nivel de familia (Otariidae). También, gracias a la presencia de ciertos restos mandibulares diagnósticos (Legoupil 1989-1990) fue posible identificar el género Arctocephalus (lobo de dos pelos), típico de latitudes más australes, aunque con una distribución discontinua, que migra por las diversas costas del norte y sur de Chile según las condiciones ambientales y oceanográficas (Guerra y Torres 1987; Sielfeld et al. 1997; Torres 1985; Torres et al. 1983a, 1983b).

Al igual que el grupo de los delfínidos, se registró un $100 \%$ de representación de partes anatómicas constituyentes a la porción axial y apendicular.

(c) Mustélidos. Fue posible identificar un solo ejemplar de la especie Lontra felina o nutria de mar (chungungo) en la Capa 7. Los restos se encontraban constituidos principalmente por la porción axial del animal, como vértebras torácicas, lumbares y sacro. A juzgar por la fusión de las carillas vertebrales se trataría de un individuo adulto que probablemente fue cazado de forma oportunista por los habitantes de Copaca 1 durante los momentos ocupacionales más tempranos.

(d) Camélidos. Solo el 3\% de los restos de mamíferos corresponde a la familia Camelidae y es prácticamente el único grupo de mamíferos terrestres identificados en la muestra $(\mathrm{N}=58)$. Esta situación no se condice con la abundante industria ósea presente en el sitio, que utiliza los huesos de estos mamíferos como materia prima para la manufactura de artefactos. Además, el 85\% de las piezas óseas de los camélidos corresponden a la porción apendicular (extremidades), a diferencia de los delfínidos y otáridos. Para el caso de los camélidos existiría un ingreso diferenciado de partes anatómicas a lo largo de la secuencia ocupacional del sitio, lo que indicaría que las presas de camélidos serían faenadas fuera de Copaca 1 , y solo se estarían descartando las extremidades.

En uno de los estratos más superficiales del sitio se identificó un fémur de un pequeño roedor de la familia Simgdontinae. A juzgar por su bajo rendimiento cárnico en relación a los otros grupos de mamíferos analizados, y a su exclusiva y baja representación, su ingreso al contexto arqueológico se debería más bien a causas naturales que a su captura.

(e) Aves. El análisis de la osteofauna aviar se realizó a partir de 685 fragmentos extraídos desde las nueve capas estratigráficas y estaría principalmente compuesto por los órdenes Suliformes, Procellariiformes y Pelecaniformes (Peña-Villalobos et al. 2013) (Figura 6). Tras elaborar los índices clásicos de zooarqueología y analizar la presencia de marcas culturales en los especímenes, se determinó un aprovechamiento de las especies Puffinus sp. (fardela), Pelecanus thagus (pelícano o alcatraz) y Phalacrocorax sp. (cormorán, yeco) encontrándose un mínimo número de individuos de 74 aves, entre los que se evidenció ciertas marcas de corte y procesamiento.

En relación al uso del recurso aviar se estima que la contribución en masa utilizable de las especies encontradas en el sitio, lo proveen mayormente las especies Pelecanus thagus (pelícano), Macronectes sp. (petrel gigante) y Phalacrocorax sp., observándose que las presas con mayor MNI (i.e. fardelas) no corresponden necesariamente a las que suministran mayor masa utilizable. De acuerdo con el análisis 


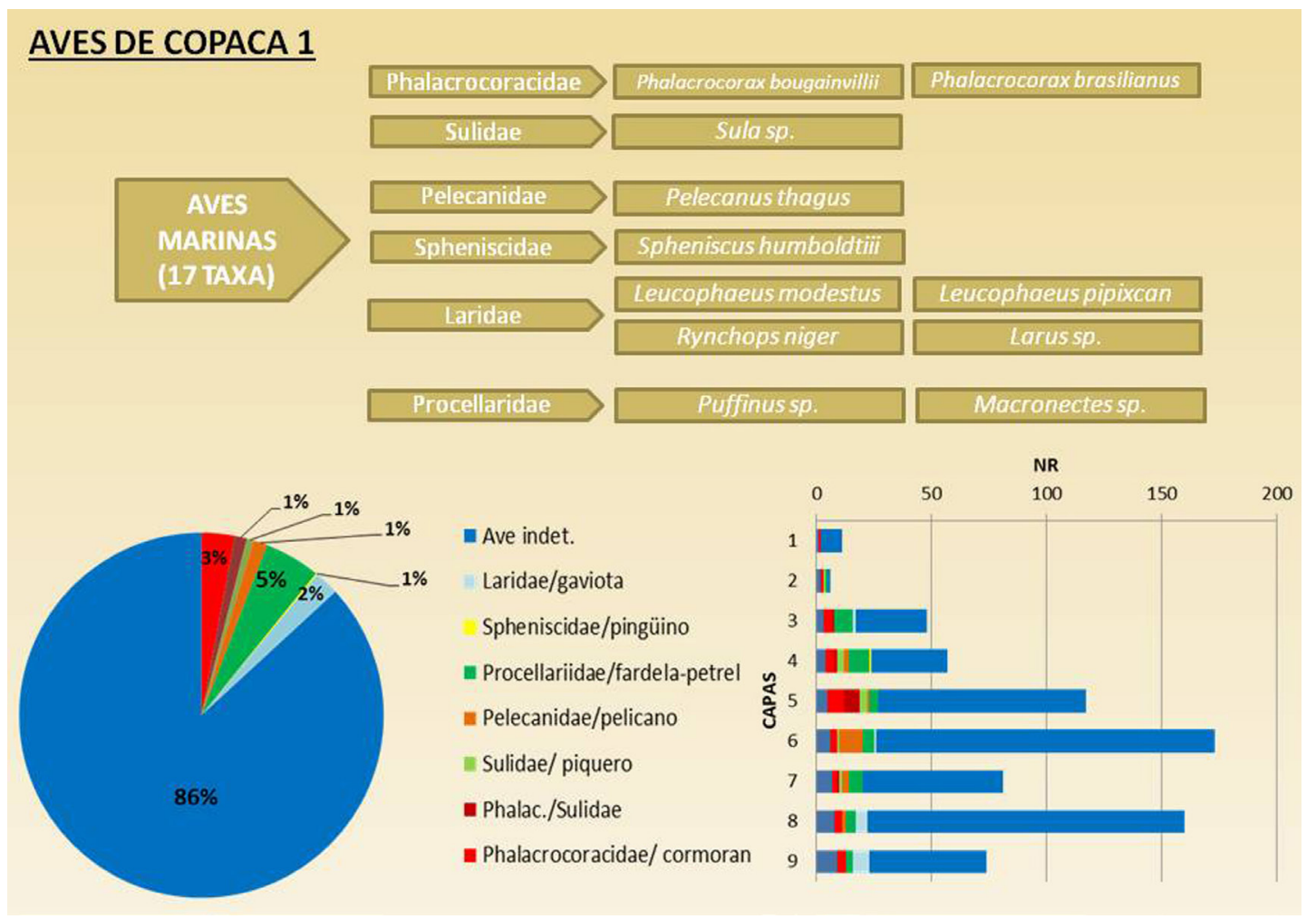

Figura 6. Aves en Copaca 1.

Birds in Copaca 1 site.

estadístico hay una presencia diferencial de elementos óseos apendiculares en las aves, con una sobrerrepresentación de especímenes de las extremidades anteriores, por sobre las inferiores. Este fenómeno, observado en múltiples estudios (Bovy 2002, 2012), respondería principalmente a la actividad cultural y no a un fenómeno postdepositacional.

(f) Peces. Se distinguieron 17 especies en la excavación y más de veinte en la columna de control (Figura 7). Esta diversidad taxonómica demuestra un acceso a todos los ambientes marinos. Incluso hay presencia de peces oceánicos, como Sarda chilensis (bonito), Seriolella violacea (cojinova), Xiphias glaudius (albacora), Tetrapturus audax (marlín) e Isurus oxyrinchus (tiburón marrajo). La subclase Elasmobranquios (sierra, pez raya y tiburón), que también se localiza en ambientes de mar afuera está presente. Entre estas especies de mar afuera, el bonito es la más representada, alcanzando 4,4\% en el sitio. En algunas unidades, como en la capa 8 , duplica esta cantidad. La subclase Elasmobranquios, en la capa 1, tiene una representación de 14,3\%, disminuyendo a $4 \%$ en las capas 2 y 3 . La albacora está presente en la capa 8 de la excavación.

La característica más notable de la ictiofauna de Copaca 1, es la fuerte presencia de Trachurus symmetricus (jurel), que se encuentra en todas las unidades de excavación del sitio en diferentes proporciones, alcanzando un promedio general de $61,2 \%$. En algunas ocasiones el jurel es desplazado como especie mayoritaria por Sardinops sagax musica (sardina), como en las capas 3 y 4 en que tiene una presencia de 50,9 y 56\%, respectivamente. El congrio (Genypterus sp.) está casi siempre presente, pero no supera el $1 \%$.

(g) Invertebrados marinos. Se analizaron los restos de invertebrados marinos de la columna de fauna del sitio. Ella presenta una gran variedad de taxa $(\mathrm{N}=58)$, distribuidas en cinco grandes grupos a nivel de clase: 11 taxa de bivalvos, 38 taxa de gastrópodos, ocho taxa de poliplacóforos (chitones), una taxa de equinodermo (erizo) y nueve taxa de crustáceos (Figura 8). 


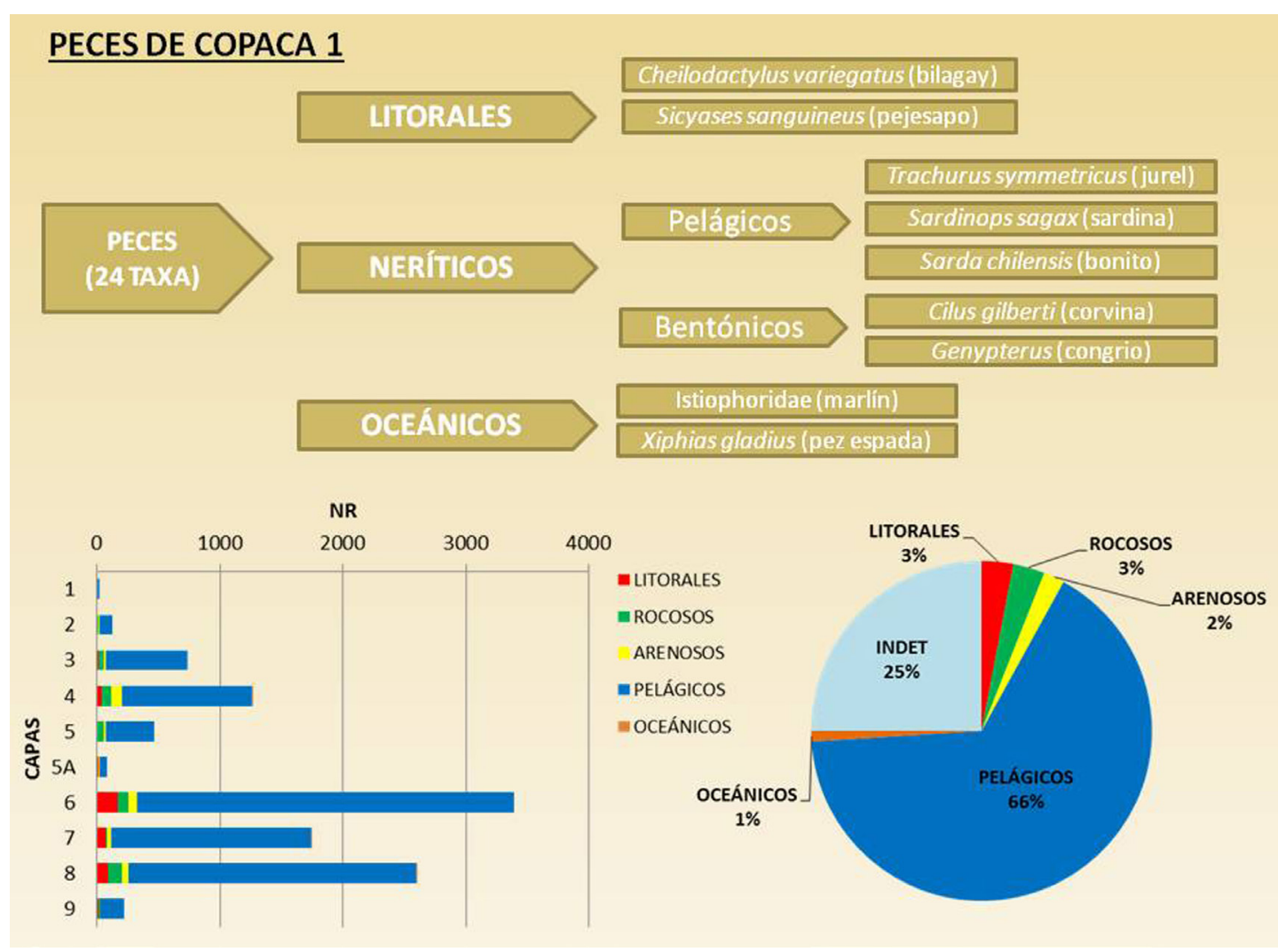

Figura 7. Peces en el sitio de Copaca 1.

Fish in Copaca 1 site.

Del conjunto de estos invertebrados solo algunas especies tienen una relevancia económica. Debido a su abundancia en cada capa estratigráfica, se presume que fueron preferentemente consumidas, o bien que fueron relevantes en la subsistencia. Ellas comprenden el 79,2\% de los invertebrados presentes en la muestra. Las más representadas son los fisurélidos, en sus diferentes tipos, siendo las más abundantes Fisurella cumingi, F. crassa y F. costata. También son importantes numéricamente Tegula atra, Loxechinus albus, los poliplacóforos (sobre todo Acanthopleura echinatta) y Concholepas concholepas.

En el primer momento del sitio, representado en la capa 9, las especies mayormente representadas para consumo fueron fisurélidos y aquí se concentran los ejemplares de mayor tamaño de Concholepas concholepas. En la ocupación posterior del Arcaico Medio, los fisurélidos continúan siendo importantes en número; no obstante, Concholepas concholepas pierde relevancia y otras taxa, como Tegula atra, los poliplacóforos y Loxechinus albus se incorporan como especies abundantes en el registro. Esta tendencia se mantiene hacia el Arcaico Tardío; es decir, las especies más abundantes son los fisurélidos y la Tegula atra. Loxechinus albus y los poliplacóforos también son abundantes, incluso más que los locos a pesar de poseer menos biomasa.

$\mathrm{El}$ análisis de longitud de las valvas de locos y lapas completas de la muestra, indica que la longitud de los locos de las capas 1 a la 8 se concentra en rangos de tamaño mediano a pequeños, entre 45 y $65 \mathrm{~mm}$, siendo los especímenes de la capa 9 los de mayor tamaño. Asimismo, los ejemplares medidos de fisurélidos presentan rangos de longitud que se concentran entre $40 \mathrm{~mm}$ y $74 \mathrm{~mm}$. Existen otras taxa como crustáceos, diferentes tipos de almejas, los mitílidos y Mesodesma donacium (macha) que en conjunto abarcan el $10 \%$ de la muestra. Ellas se distribuyen de manera uniforme en los momentos ocupacionales del sitio. También es relevante la presencia de Mesodesma donacium en la capa 9, 


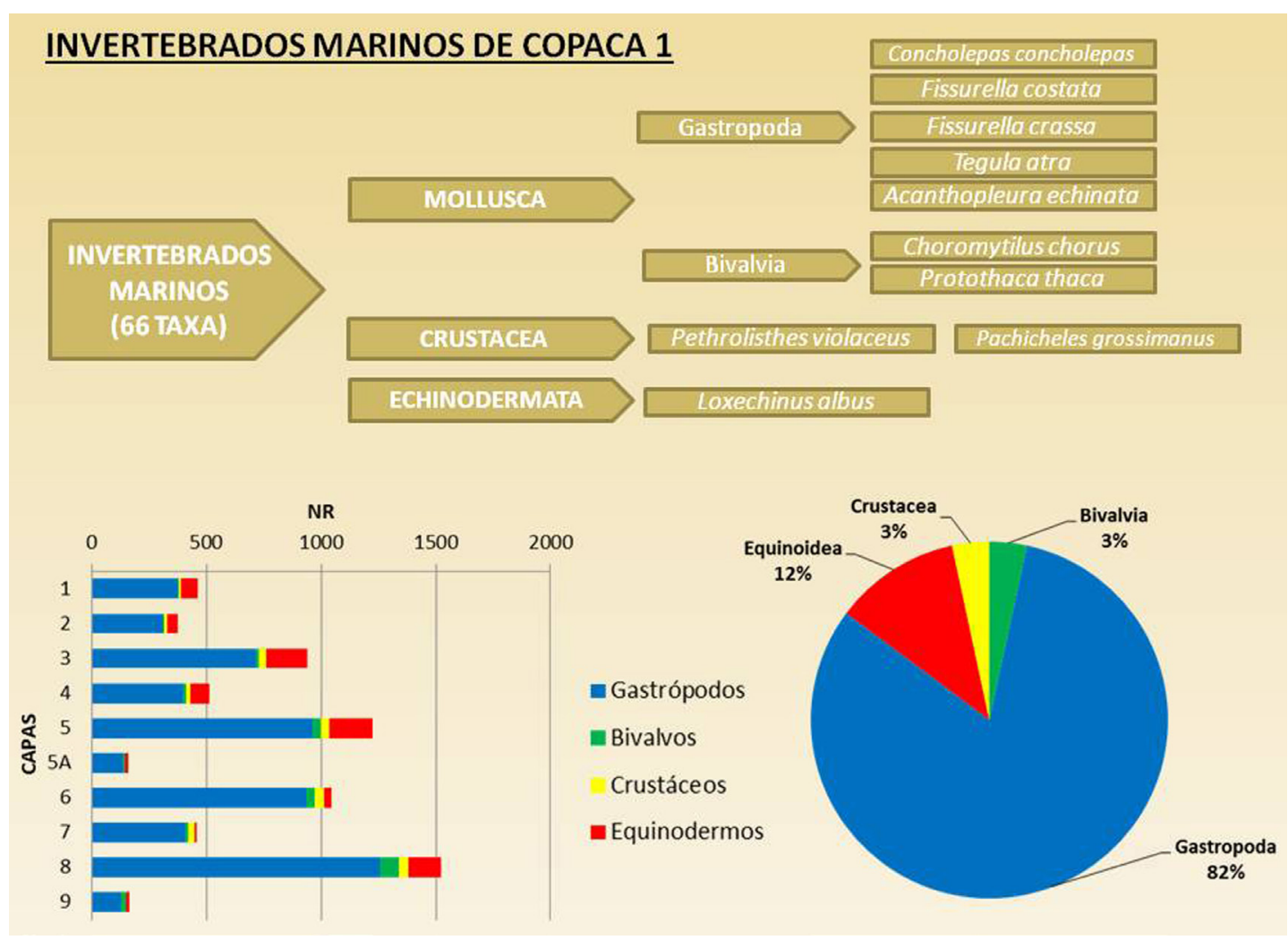

Figura 8. Invertebrados marinos en Copaca 1.

Marine invertebrates in Copaca 1 site.

lo que podría indicar, debido a los requerimientos de hábitat de esta especie, la presencia de una playa arenosa de grano fino, aún no cubierta por la transgresión holocénica del mar en las inmediaciones del asentamiento en los tiempo de su primera ocupación. Un grupo de invertebrados marinos que no se considera de importancia económica debido a su baja biomasa, también está representado. Estos son los epibiontes y los caracoles pequeños como Diloma nigerrima, Turritela cingulata y Prisogaster niger y representan el 14\% de la muestra total de invertebrados marinos. Los epibiontes ingresan al conchal adheridos a otras taxa mayores, mientras que la presencia de los caracoles pequeños en el depósito puede deberse también a esta situación o a una recolección intencional para fines diferentes a los alimenticios.

Las principales taxa de crustáceos de la muestra, se caracterizan por habitar en microambientes rocosos, de suelo duro y playas de bolones; Pachicheles grossimanus (cangrejo del chascón) habita en directa relación con algas como Lessonia, adhiriéndose al disco basal del alga, mientras que Pethrolisthes violaceus (cangrejo violeta) vive en las frondas de las algas. Debido a que el tamaño estimado de los crustáceos de la muestra es pequeño, la presencia de ellos podría ser una evidencia indirecta de la explotación de algas como Lessonia.

\section{Instrumentos líticos y prácticas económicas}

Los grupos que generaron los depósitos domésticos de Copaca 1, tallaron recurrentemente sílice y andesita, recuperándose en el sitio un enorme conjunto de desechos de talla $(\mathrm{N}=7.503)$ e instrumentos ( $\mathrm{N}=338$ ) (Figura 9). En términos generales, los desechos de andesita evidenciaron mayor frecuencia de corteza y mayores tamaños, sugiriendo la talla expeditiva de guijarros, a diferencia de los desechos de sílice, en general secundarios, de menor tamaño y con cierta proporción de talones facetados. Por su parte, los instrumentos mostraron 


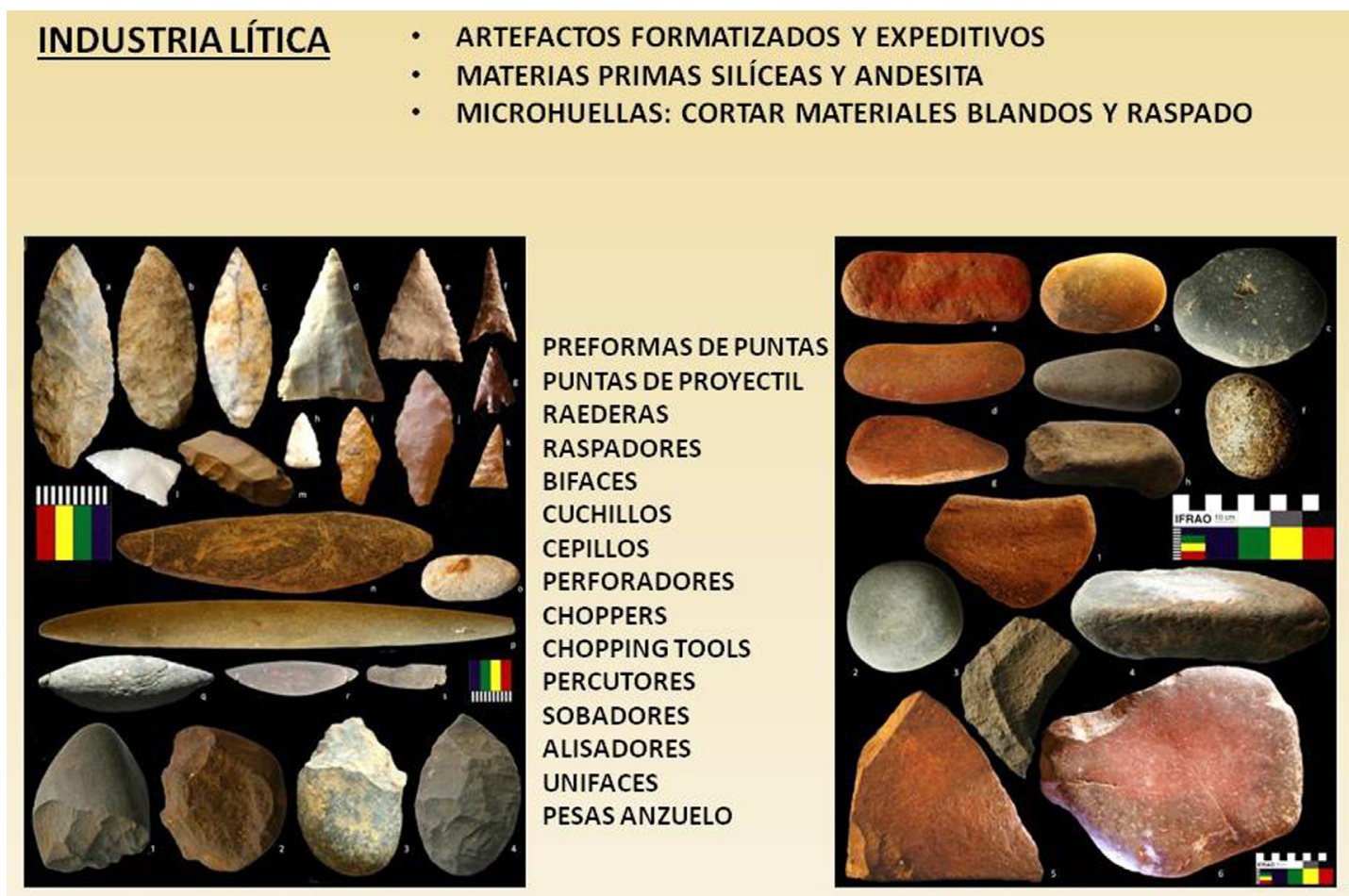

Figura 9. Instrumentos líticos de Copaca 1.

Lithic artefacts in Copaca 1.

en su mayoría bordes filosos, en ambas materias primas, destacando la alta frecuencia de microhuellas de corte (p.ej. estrías). No obstante lo anterior, un importante conjunto de instrumentos líticos no presentó talla alguna, siendo abundante el uso de guijarros de andesita en actividades que requirieron la abrasión o frotado de otras materias primas. Los sobadores $(\mathrm{N}=88)$ generalmente evidenciaron grupos de estrías en el centro de ambas caras. Estas microhuellas se asociaron significativamente con adherencias orgánicas amarillas de probable origen animal $^{7}$, lo que sumado a grosores muy reducidos, sugirieron prácticas de frotado sobre materiales blandos, probablemente cueros de mamíferos. En varios casos las caras planas presentaron asociación con adherencias minerales rojizas, mientras que en otros se registraron desportilladuras en los extremos por actividades de percusión $(\mathrm{N}=13$ y $\mathrm{N}=10$, respectivamente). Entre estos últimos, el $50 \%$ evidenció asociación con las mencionadas adherencias, sugiriendo prácticas de frotado y percusión de minerales de fierro o sulfuros de mercurio. Casos minoritarios demostraron el pulverizado fino de dichos minerales rojizos $(\mathrm{N}=5)$. En términos generales, los sobadores presentaron amplia distribución estratigráfica (Figura 10), denotando actividades artesanales abrasivas extendidas en el tiempo, aunque con sus mayores intensidades en las capas 3 y 4 . Complementariamente, los grandes sobadores pasivos evidenciaron desgastes macroscópicos cóncavos ( $\mathrm{N}=8)$ y en surco $(\mathrm{N}=6)$, generados durante el formatizado abrasivo de otras materias primas (p.ej. ósea). Estos grupos también utilizaron cantos rodados principalmente como percutores $(\mathrm{N}=20)$, presentando desportilladuras en sus extremos activos, aunque también el frotado abrasivo de mineral rojizo como funcionalidad secundaria. Finalmente, también fueron identificadas dos pesas de andesita para anzuelos compuestos, de morfología longitudinal biconvexa y con extremos aguzados, confeccionadas mediante abrasión.

Estos grupos tallaron guijarros de andesita, obtenidos en playas locales, confeccionando ciertos tipos de instrumentos expeditivos. Los choppers resultaron un instrumento muy frecuente $(\mathrm{N}=38)$, especialmente aquel de filo frontal y borde activo convexo (sensu Aschero 1983), siendo el instrumento con mayores frecuencias de microhuellas de corte 
en bordes activos $(18,2 \% ; \mathrm{N}=14)$ (García-Albarido 2012). Las alteraciones observadas sugieren corte y raspado de materiales blandos, por ejemplo carne y cuero de mamíferos marinos y terrestres. La distribución de los choppers comprometió todas las capas, aunque concentrándose en las ocupaciones iniciales (capas 7 y 8). De igual modo, se tallaron chopping tools $(\mathrm{N}=6)$ con un borde activo corto de morfología convexa. Estos instrumentos se encontraron asociados a las primeras ocupaciones del sitio (capa 7). Las actividades de talla lítica también requirieron de grandes cantidades de sílice, siendo este transportado desde los afloramientos orientales de la cordillera de la costa. Con esta materia prima se confeccionaron instrumentos de bordes filosos, destacando raederas, raspadores y bifaces (Figura 11). Las raederas $(\mathrm{N}=21)$ corresponden principalmente a las de filo lateral $(\mathrm{N}=11)$ y denticuladas $(\mathrm{N}=8)$ (sensu Aschero 1983). Las raederas de filo lateral se asocian a las últimas ocupaciones del sitio, mientras que las de filo dentado, a las primeras ocupaciones. Estos instrumentos se usaron para cortar materiales blandos ( $\mathrm{N}=13)$, identificándose en muchos casos las microhuellas correspondientes.

Los raspadores y bifaces también fueron tallados en sílice ( $\mathrm{N}=19$, en ambos casos), y tuvieron una amplia distribución en todas las capas. Los bifaces representaron un $13,3 \%$ de los instrumentos con microhuellas generadas por acciones de corte y $13,7 \%(\mathrm{~N}=4)$ de los instrumentos usados para cortar y raspar. Entre los raspadores 5,3\% (N=4) evidenció microhuellas generadas por acciones de corte y $20,7 \%(\mathrm{~N}=6)$ por corte y raspado, demostrando que las tipologías morfológicas no se corresponden necesariamente con determinadas funcionalidades únicas. Los cuchillos tallados en lascas de sílice $(\mathrm{N}=9)$ presentaron directa relación con las cuatro capas superiores del sitio, mientras que otros tipos morfológicos, como raclettes $(\mathrm{N}=5)$, cepillos $(\mathrm{N}=5)$ y perforadores $(\mathrm{N}=2)$ son poco frecuentes. La talla de puntas líticas quedó evidenciada por un importante conjunto de preformas en sílice $(\mathrm{N}=24)$ y por puntas finalizadas $(\mathrm{N}=3)$, destacando aquellas de morfología bipunta, no registrándose limbos triangulares, aletas o pedúnculos (cfr. Orquera y

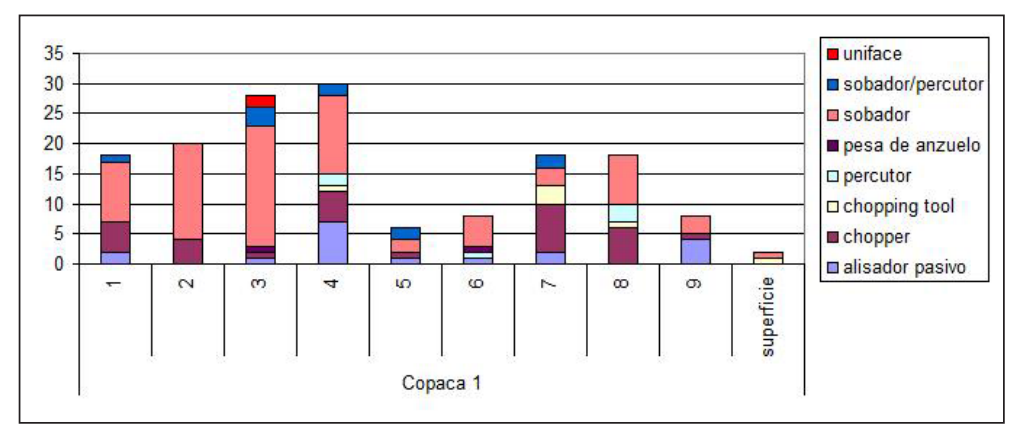

Figura 10. Distribución estratigráfica de tipos morfológicos en andesita en Copaca 1. Stratigraphic distribution of morphological types in andesite in Copaca 1.

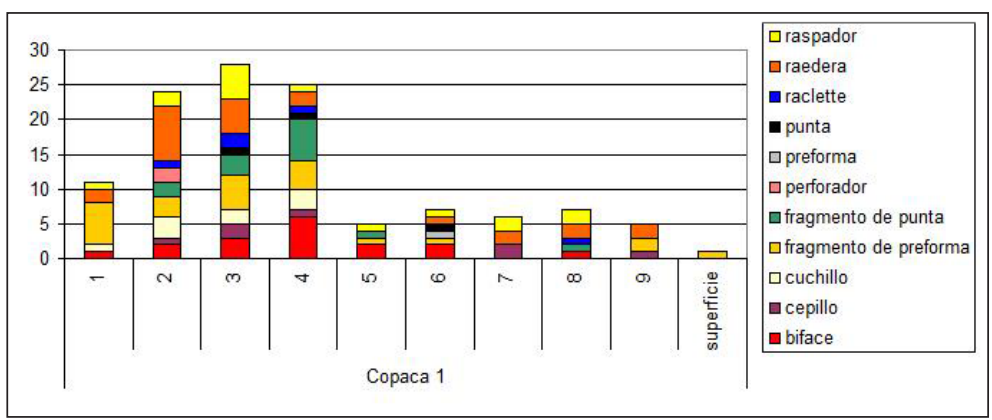

Figura 11. Distribución estratigráfica de tipos morfológicos en sílice en Copaca 1. Stratigraphic distribution of morphological types in silica, in Copaca 1 site. 
Piana 1986:57). Todos estos antecedentes sugieren el uso de grandes puntas para la cacería de mamíferos marinos y terrestres.

Artefactos formatizados. Los artefactos formatizados de Copaca 1 (Tabla 2) se relacionan principalmente con el instrumental de pesca, caza y recolección, característico de poblaciones marítimas. Encontramos anzuelos de concha, pesas óseas, pesas líticas, barbas óseas de arpón, fragmentos de cuerpos de arpones, gancho óseo de potera, puntas líticas pedunculadas y lanceoladas o bipuntas e instrumento mariscador de hueso. Acompañando a este conjunto existen además otros objetos fragmentados de hueso, de cuerpos alargados, extremos romos y/o apuntados, con bordes activos y que no estarían relacionados con las actividades de subsistencia. Algunos pudieron usarse como herramientas en la manufactura de otros instrumentos, como por ejemplo cinceles para la percusión indirecta sobre materias primas líticas (Santander 2010) o como punzones en el trabajo en cuero. También existen algunos utensilios de uso doméstico como cucharillas o espátulas ${ }^{8}$.

Para la fabricación de los instrumentos óseos se aprovecharon los huesos de camélidos, mamíferos marinos como otáridos y aves costeras (Figura 12). Otro material importante para la confección de artefactos son las conchas de invertebrados marinos. Entre estos encontramos cuatro fragmentos de valvas de Choromitylus chorus con bordes modificados que pudieron servir eventualmente de cuchillos. De este mismo material se han encontrado cuatro anzuelos de vástago recto, realizados con las conchas de este bivalvo $^{9}$ (Figura 13). También se localizaron cuentas tubulares de concha blanca de Turritella cingulata.

\section{Discusión}

\section{Acerca de la cronología}

(1) El aporte de las dataciones de la capa 9 del conchal de Copaca 1, documentó la Fase III (9.000 a 6.000 a.p.) de Llagostera (2005), con lo que se contribuye a llenar un hiato de 3.000 años de ausencia de fechados en el registro arqueológico de la costa de Antofagasta. Esta capa, fechada en 7.799 a.p., da inicio a la ocupación humana del sitio por parte de poblaciones que permanecerán allí por más de 2.000 años.

(2) Salvo esta fecha excepcional, nuestra serie arqueométrica de más de una docena de fechas
(Tabla 1) casi la totalidad de ellas se agrupa en un milenio, entre el 4.500 y el 5.700 a.p. Este período corresponde a parte de la Fase IV y la primera mitad de la Fase V de Llagostera (2005). Con los datos señalados se confirma la hipótesis de este autor que "la amplia distribución y potencialidad de los yacimientos demuestra que durante la Fase IV se consolida una exitosa adaptación que permite la existencia de enclaves persistentes a lo largo de prácticamente toda la costa de los litorales árido y sub árido" (Llagostera 2005:130).

\section{Acerca de las condiciones ambientales}

Una revisión de la literatura paleoambiental demuestra que durante este periodo las condiciones ambientales no fueron iguales a las actuales. Así, los recursos de agua fresca en la costa estarían supeditados principalmente a las lluvias provenientes del altiplano, las que recargarían los acuíferos que brotan como vertientes en la costa arreica. Por otra parte, tanto en la actualidad como en el pasado, escasos eventos de lluvias provenientes del suroeste, y generalmente asociados a fenómenos ENSOS de gran intensidad, podrían aportar a la hidrología de la zona, pero posiblemente como eventos aluviales catastróficos (Vargas et al. 2000, 2006) más que como recursos de agua de carácter permanente.

Las evidencias paleoclimáticas del altiplano desde donde provienen los acuíferos que pudieron alcanzar la costa, sugieren que las condiciones de mayor aridez de todo el Holoceno se habrían dado en torno a los 9.000-7.000 a.p., desde este momento y hasta los 4.000 a 3.000 a.p., el clima habría sido más árido que el actual (Grosjean et al. 2001, 2003), con una reversión hacia condiciones algo menos áridas, similares a las actuales, en torno a los 6.0005.200 a.p (Bobst et al. 2001; Grosjean et al. 2001, 2003; Latorre et al. 2002; Pueyo et al. 2011). Una tendencia hacia las condiciones climáticas actuales posterior a la fase árida del Holoceno Medio, habría ocurrido de forma gradual.

En la costa, son escasos los registros paleoambientales disponibles y la mayoría se asocia a temperaturas superficiales del mar y/o productividad marina (es decir producción de biomasa marina, la que puede repercutir en cada nivel de la cadena trófica, desde productores primarios como microalgas hasta mamíferos marinos y aves costeras). Así, un registro de sedimentos marinos, 


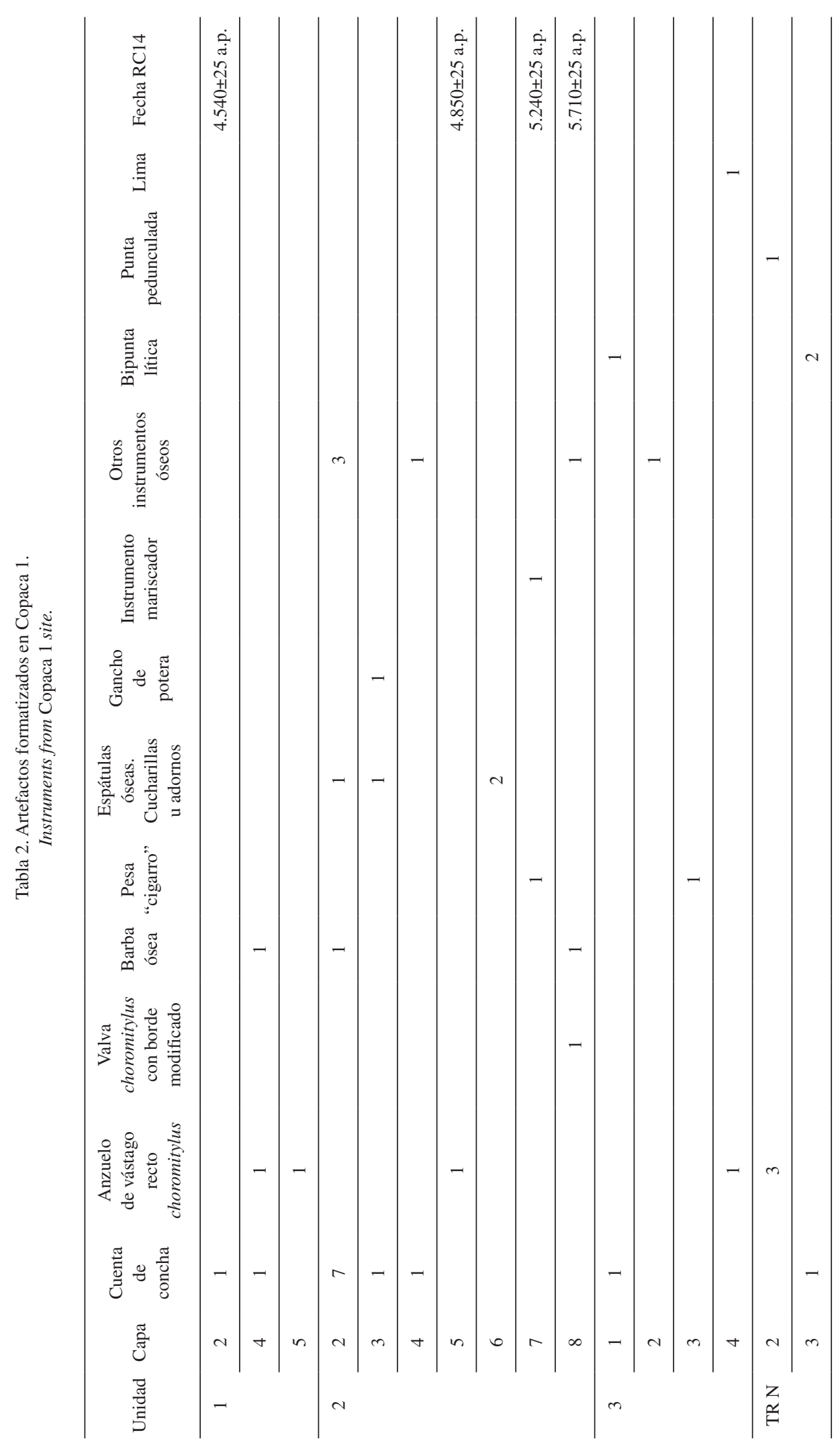




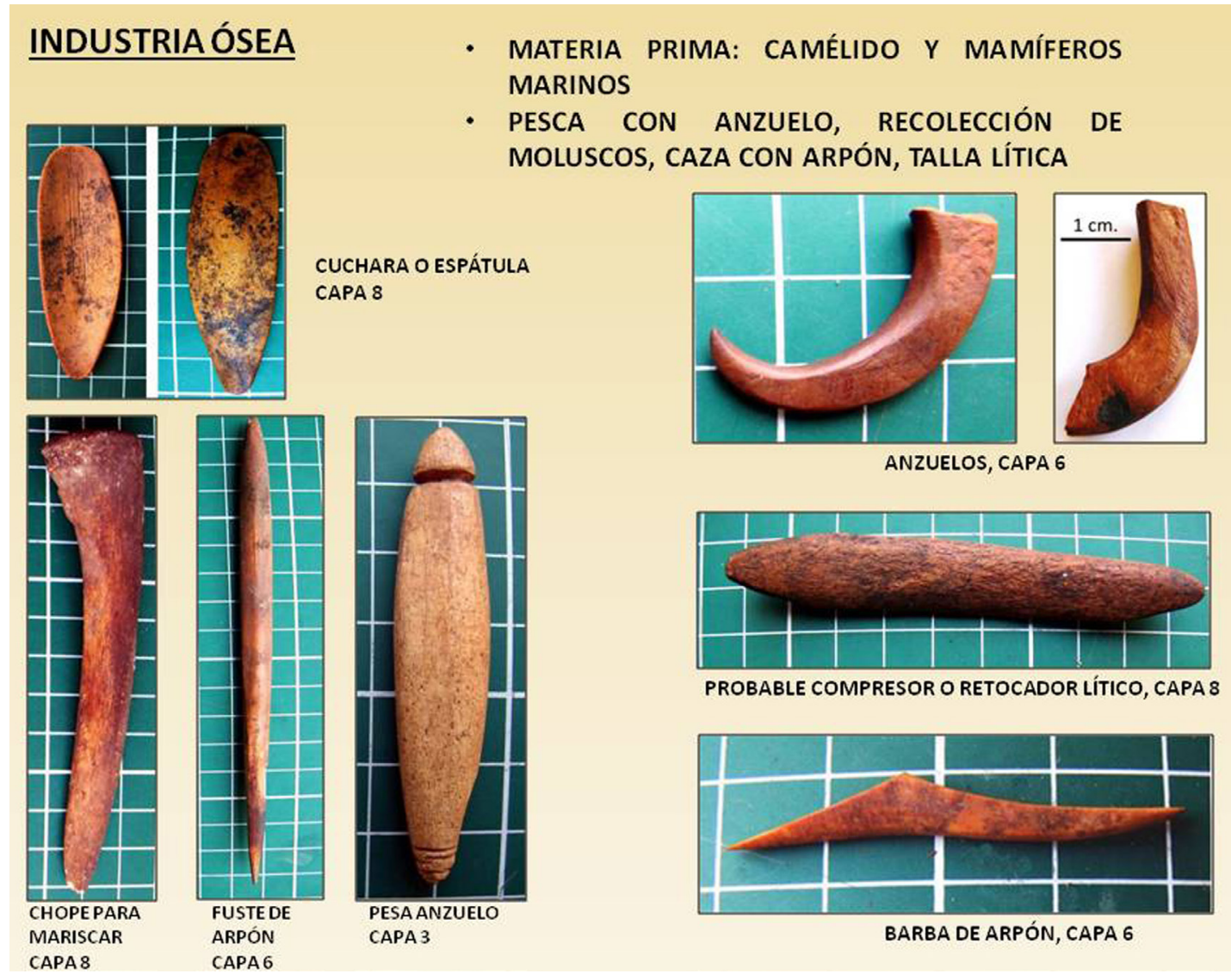

Figura 12. Instrumentos de Copaca 1. Industria ósea.

Instruments from Copaca 1 site. Bones industry.

muestreado a $2.500 \mathrm{~m}$ de profundidad frente a las costas de Antofagasta (24\% $\mathrm{S}$; GeoB 7112-5) muestra los menores valores de productividad e intensidad de surgencia de aguas profundas (ricas en nutrientes, que aportarían a una mayor productividad marina) de los últimos 19.000 años, entre 13.000-4.000 a.p. con un pulso de relativamente mayor productividad e intensidad de surgencia focalizado en torno a 8.500-7.200 a.p. (Mohtadi et al. 2004).

Complementariamente, registros de isótopos de oxígeno y carbono en moluscos obtenidos desde sitios arqueológicos al sur del Perú, sugieren que en torno a 8.000 a.p. las temperaturas superficiales del mar en la costa fueron del orden de $1-4{ }^{\circ} \mathrm{C}$ inferiores a las actuales (Carré et al., 2005). Asimismo, cambios en el efecto reservorio marino en las costas del Norte Grande sugieren también un anticiclón robustecido e intensificación de la surgencia costera entre 10.400-6.840 a.p. mientras que entre 5.180-1.160 a.p. una mayor influencia de aguas subtropicales y debilitamiento de la surgencia costera (Ortlieb et al. 2011).

Por otra parte, la dinámica del fenómeno El Niño, que parece no ser muy determinante en términos hídricos en esta zona, pero sí puede ser un factor a considerar en términos de disponibilidad de otros recursos (p.ej. marinos y vegetales), muestra la menor actividad de todo el Holoceno, en torno a 7.800-4.700 a.p. (Rein et al. 2005) y la mayor actividad después de 2.000 a.p. (Moy et al. 2002; Rein et al. 2005; Riedinger et al. 2002).

\section{Acerca de la bioantropología, modalidades funerarias y modos de vida}

En este sitio se han registrado prácticas funerarias novedosas para el arcaico costero. El individuo 1 se encontraba en la capa 5, dentro de una estructura subterránea subcircular, sobre un piso de arcilla especialmente preparado, un 


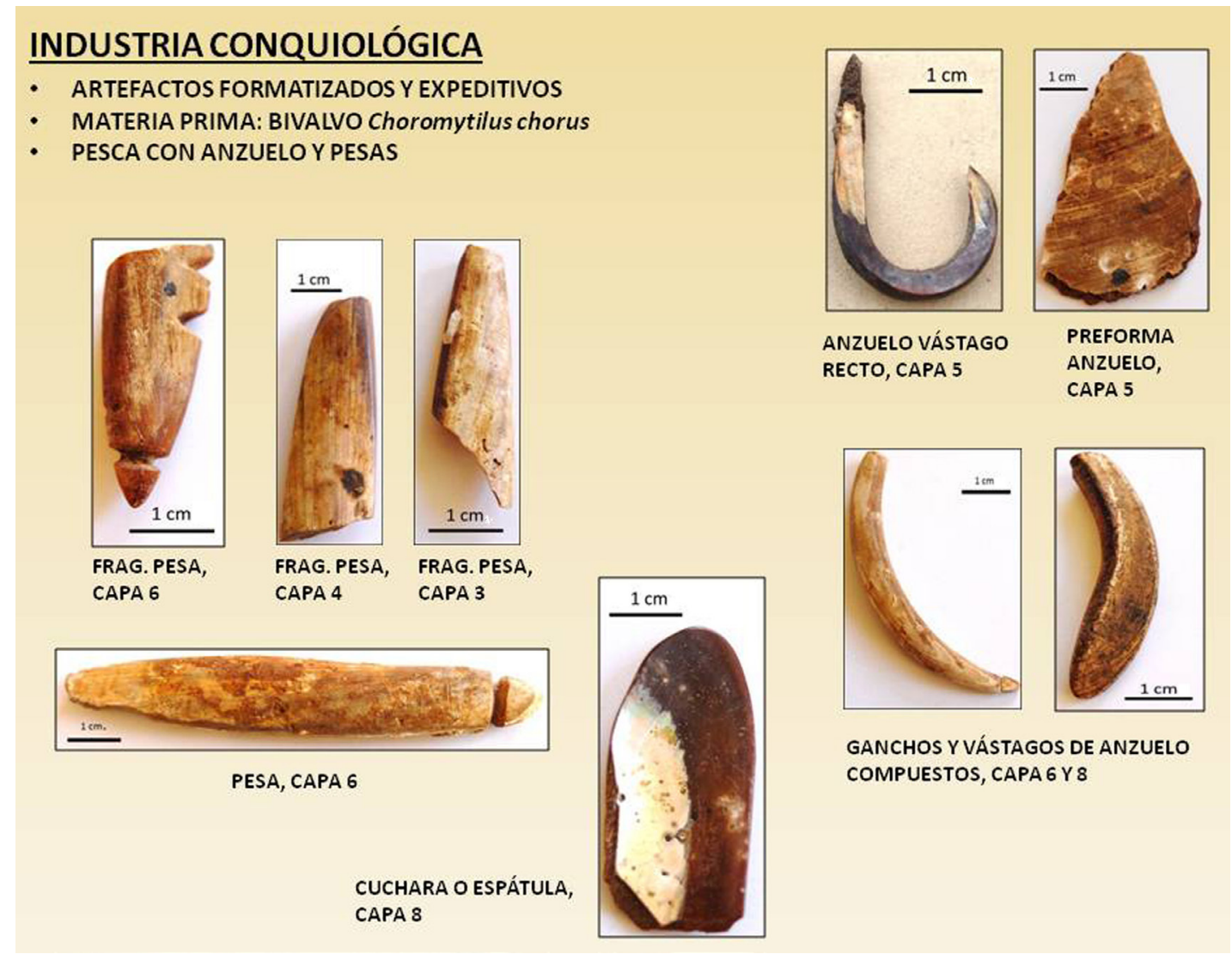

Figura 13. Instrumentos de Copaca 1. Industria conquiológica. Instruments from Copaca 1 site. Conquiological industry.

patrón inverso al observado en otros sectores de costa arreica que presentan entierros ubicados bajo la capa preparada o pisos-sellos (Llagostera 1989:70; Núñez et al. 1971; Zlatar 1983:22). Los rasgos mortuorios del individuo y especialmente el desplazamiento de las vértebras cervicales y su reemplazo por las conchas de erizos, sumado a los guijarros - pintados de rojo- colocados como extensión de ambas manos constituyen rasgos inéditos no descritos anteriormente (Andrade et al. 2016). Sin tener una respuesta clara, nos inclinamos a pensar que se trataría de algún rito mortuorio, no correspondiendo su posición a disturbaciones o cualquier otro evento postdepositacional. Finalmente, entre las piernas del individuo en calidad de entierro secundario-ofrenda, se depositó un infante (individuo 4). Un rasgo también novedoso es el hallazgo en capa 6 de otros dos entierros secundarios desarticulados e incompletos cuyas extremidades inferiores se encontraron depositadas como un "paquete" ordenado junto a sus respectivos cráneos. A pesar de la ubicación de estos últimos cuerpos, los fechados de colágeno obtenidas para los cuatro individuos, son contemporáneos. Todas estas modalidades funerarias son atípicas para el Arcaico costero.

En cuanto a modos de vida, el análisis bioantropológico (Andrade et al. 2016) permite sugerir que las actividades realizadas por el individuo 1, pudieron consistir en el uso de remos, la natación, la pesca y caza submarina y el uso de arpones (Jurmain y Kilgore 1995; Kennedy 1989; Molnar 2006). Así, cabe la posibilidad que al menos este individuo estaba explotando recursos lejanos a la línea costera y en las profundidades marinas. La presencia de exostosis auditiva externa bilateral sugiere prácticas de buceo (Standen et al. 1995). Este individuo no presenta evidencias de caries, lo que se condice con una dieta rica en proteínas animales que junto con la presencia de un desgaste 
dental plano y bastante severo, corresponde a una dieta típica de cazadores-recolectores costeros (Andrade 2011; Andrade et al. 2016; Standen y Núñez 1984).

\section{Probable navegación en épocas arcaicas}

Los antecedentes entregados nos llevan a discutir acerca de la probable navegación en épocas arcaicas. Para Llagostera $(1989,2005)$ la adopción de la balsa representa la etapa final del proceso de maritización de los pueblos costeros prehispánicos y ocurriría en un período post-Arcaico. Con ello se ampliaría el acceso a recursos marinos y desde un punto de vista adaptativo significaría un salto hacia un nuevo nivel energético. Las nuevas poblaciones tendrían acceso a peces de mar abierto, como los atunes y dorados; a peces semiabismales, como el congrio (Genypterus) y los cetáceos (Globicephala). Llagostera (1990) postula que la presencia de Genypterus en los sitios costeros de la segunda región sería un bioindicador de la navegación en la zona y según sus estudios estaría practicándose por los 230 años d.C. El congrio se registra en nuestros sitios arcaicos de Copaca 1, Guasilla 2 y Mantos de la Luna, en bajas proporciones, entre 0 y $0,99 \%$ en cada unidad. Por el contrario, en los sitios tardíos (Cobija 1 Norte y Cobija 24) tiene presencia de $11,8 \%$, lo que confirmaría la tesis de Llagostera respecto a este bioindicador.

En efecto, para fundamentar la idea de una navegación temprana (al menos desde el Arcaico Medio), al no contar con evidencia directa, se ha mantenido el uso del concepto de bioindicador propuesto por Llagostera (1990). En el caso de la evidencia icitiológica de Copaca 1, el uso de dicho concepto es apropiado ante la presencia de restos de Xiphias gladius (albacora), Isurus oxyrinchus (tiburón marrajo) y marlín (Istiphoridae). En términos generales, se ha señalado que los individuos de estas especies son altamente migratorios y se desplazan de manera individual. Son peces pelágicos de aguas oceánicas (Castilla et al. 2007; Chong et al. 2009; Letelier et al. 2009).

Se han reconocido las embarcaciones del Médano como balsas de cuero de lobo (Mostny y Niemeyer 1983:47). Si bien las noticias sobre este tipo de embarcación en la documentación histórica se extienden hasta mediados del siglo XX, la arqueología ha recuperado evidencias de estas embarcaciones en sitios prehispánicos tardíos y de contacto con los inkas (Núñez 1986:20-26). Otras evidencias se han encontrado en asociación con cerámica del Período Medio de San Pedro de Atacama, específicamente en Abtao 5, donde se encuentra asociada a cerámica Roja Grabada, datada entre el 400 al 700 d.C. (Llagostera 1990:44). Para Berenguer (2009), estas pinturas podrían ser hasta 600 años anteriores a esta fecha y toma cautela en identificarlas a todas como balsas de cuero de lobo marino, señalando la conocida miniatura de balsa de totora ofrendada en la desembocadura del río Loa y fechada en el 215 d.C. (Núñez 1989:13-14).

Para Salazar et al. (2010) la asociación de restos de congrio y albacora sería el bioindicador de navegación para las poblaciones que ocuparon la zona costera de la quebrada de Mamilla en las cercanías de Tocopilla. La presencia combinada de estas dos especies entre los restos arqueológicos de la ocupación del período Intermedio Tardío de Mamilla reforzaría aún más la tesis de Llagostera. Núñez (2003) sugiere que las primeras embarcaciones confeccionadas en el norte, fueron realizadas en época Chinchorro. Simples atados de fibra vegetal, caballitos de totora o chinchorros habrían servido como embarcaciones. Aportando a la hipótesis de la navegación temprana, Núñez y Contreras (2009) señalan un modelo de "balsa Chinchorro" dibujada por Augusto Capdeville de entre objetos encontrados en el cementerio arcaico de Punta Morada, en Taltal, confiando en la honestidad y riguroso desempeño del investigador taltalino.

En Copaca 1, las evidencias ictiológicas muestran un acceso a todos los ambientes marinos desde el Arcaico Medio, lo que puede indicar uso de tecnologías apropiadas para la pesca en mar afuera. En efecto, hay presencia de Xiphias glaudius, marlín, bonito y Elasmobranquios (sierra, rayas tiburones), todos de mar afuera. Estas evidencias junto con las mencionadas en el análisis bioantropológico, también abonan la hipótesis de una navegación temprana.

En este mismo sentido, sin duda la capa 8 del yacimiento Copaca 1 es portadora del mayor cúmulo de evidencias ictiológicas. En este marco, quisiéramos destacar que la posibilidad de tener embarcaciones y adentrarse en busca de recursos pelágicos, no conlleva la necesidad de un conocimiento propio del concepto actual de "navegar" (dirigido a uso de velamen, quilla estabilizadora y travesías de considerables 
distancias), sino más bien, con este concepto de navegación nos referimos a la capacidad de fabricar balsas con buena estabilidad que mediante un sencillo sistema de impulso (como lo son los remos), podrían facilitar el acceso al área batitudinal marina, y por ende poder extraer recursos marinos de mayor tamaño y biomasa, maximizando en este sentido, el uso del océano para la supervivencia.

Pensamos que dicha capa 8 , que tiene la mayor diversidad de especies posibles de ser vinculadas con pesca desde embarcaciones o balsas: como el Genypterus sp. (congrio), elasmobranquio (tiburón) y bonito (atún), este último con un MNI de cinco individuos, podría ser un bioindicador temprano del uso de sistemas de desplazamiento marítimo por parte de los habitantes que ocuparon Copaca 1 para dicho período. Debe destacarse también, que en este mismo horizonte estratigráfico se registraron otros taxa ictiológicos como el jurel, con un MNI 52 individuos, siguiéndole la cabinza con seis especímenes y el billagay con cinco.

\section{Etnografía de Caleta Buena}

Para poder realizar las afirmaciones antes propuestas, hemos recurrido a la experiencia etnográfica que puede permitir sustentar nuestras proposiciones y conocer las tradicionales formas de capturar dichos recursos en la costa de estudio. Así, hemos realizado una investigación etnográfica, en la comunidad pescadora de Caleta Buena, comuna de Tocopilla, Región de Antofagasta, la cual se encuentra a solo $15 \mathrm{~km}$ del sitio en estudio (Rubio 2012). Dicha investigación, considera especialmente la gran experiencia, conocimiento y comprensión de un experto local, pescador y buceador, Don José Flores, apodado "el Filipino". En lo que se refiere al congrio (Genypterus sp.), Don José nos ha enseñado cómo se pescaba cuando en su tiempo también se especializó en la captura de dicho pez. Así, el congrio se solía capturar en este litoral de forma artesanal bajo la antigua técnica denominada "manear". Esto significa pararse en el bote con una línea de pesca en cada mano y un anzuelo de considerable tamaño, y comenzar a subir y bajar una mano y la otra de forma secuencial, vale decir como si fuese un péndulo. Don José describe explícitamente que al arrojar el anzuelo se debe sentir que este toca fondo para luego subirlo solo un poco, a modo de tentar a dicho pez. Así, luego de este proceso, uno comienza a "manear" hasta que uno de los anzuelos en cada mano pique. Esta es la antigua y regular forma que se utilizaba para capturar al congrio. No obstante, bien sabemos que hoy en día los pescadores usan otros métodos como el espinel, que consiste en una línea con muchos anzuelos, que se suele dejar toda la noche y al otro día se recoge (Rubio 2012). En este sentido, la pesca del congrio requeriría también del uso de embarcaciones o balsas para su captura.

El ambiente de residencia de Genypterus sp. es bentónico, lo cual significa que su ciclo de vida depende del fondo marino. Si bien se ha definido como bentónico costero, es posible que para acceder a su hábitat se requiera del uso del algún tipo de embarcación, posiblemente no muy alejado del borde costero. Actualmente estos peces son capturados por buzos artesanales usando una fija, además de redes de arrastre y espinel de fondo (Reyes y Hüne 2012).

En cuanto a la captura de "elasmobranquios" (tiburones), según Don José, estos suelen "picar" solo en ocasiones, comúnmente cuando se hallan en busca de otros peces de mayor tamaño en aguas abiertas, donde suelen habitar dichos escualos. En este sentido, los grupos humanos prehistóricos en estudio se podrían haber adentrado bastante en aguas abiertas con sus embarcaciones, en donde pudieran haber capturado algún tiburón. No obstante, esta situación también podría haberse dado en aguas más cercanas a la costa, por lo que no podemos asumir con certeza un adentramiento de dichas poblaciones hacia aguas abiertas. Lo que no podemos negar, es que su captura debió requerir del uso de embarcaciones, puesto que según nos informa Don José, sería prácticamente imposible capturarlos desde la orilla, puesto que las líneas de pesca que se ocupan en los requeríos son muy finas paras peces pequeños, por lo que no hubiese resistido la fuerza de un escualo; Don José opina que tiene que haber sido con una línea de bastante grosor o con el uso de un arpón (Rubio 2012).

Sobre la base de la etnografía realizada, el acercamiento de recursos pelágicos a la costa se relaciona con ciertos cambios de corrientes marinas y cambios del nivel termal de las aguas por eventos como el fenómeno del Niño. Don José nos relata que este suceso climático trae a aguas costeras (pero no al borde costero propiamente tal) recursos piscícolas de aguas interiores y de aguas más cálidas, como tiburones, palometas, atún y peje perro (Rubio 2012).

Por otra parte, otro factor de acercamiento a aguas menos profundas de especies pelágicas, se relaciona con la pérdida de la orientación de 
individuos más jóvenes. En este sentido, Don José señala que muchas veces ha visto albacoras de mediano y pequeño tamaño pasar por el costado de su bote. Lo mismo le ha ocurrido con diferentes tipos de tiburones y cetáceos. Una última posibilidad de acercamiento a la costa de especímenes pelágicos, que nos aporta la etnografía, se relaciona con el seguimiento de estos animales a diferentes tipos de bancos de peces más pequeños y por debajo de ellos en la cadena trófica. Un buen ejemplo, podría darse por la visita a aguas menos profundas de bonito y atún en busca de sardinas y jureles, y por ende, seguidamente la presencia de albacoras en busca de estos mismos bonitos y atunes. Así, cuando un buen banco de sardinas pasa cercano a la costa, vendrán con él seguidamente los otros especímenes por encima de ellos en la cadena trófica. De la misma manera, estas sardinas, se habrán acercado a la costa impulsadas por los recursos por debajo de ellas en la cadena trófica que se han acercado también a la costa. Lamentablemente cada día son menos visibles estos acercamientos esporádicos de grandes bancos de peces con un bajo nivel trófico a la costa debido a la pesca industrial indiscriminada en altamar.

En este ámbito de recursos marinos, la etnografía nos señala algunas formas de advertir la llegada de cardúmenes hacia zonas aledañas al litoral, como son las "pajaradas". Don José, relata que los peces que son de roca viven allí todo el tiempo, no son migratorios. Por otra parte, el jurel, la sardina, el bonito y otros que son migratorios y pelágicos circulan por todo tipo de fondos marinos ya sean rocosos o arenosos, de esta manera, cuando los cardúmenes de estos últimos pasan por enfrente de las caletas, los pescadores salen a cazarlos. Los pescadores actuales al ver a las aves marinas (las pajaradas en el mar), tirándose piqueros o sobrevolando algún lugar en especial, ellos saben que por allí está pasando un cardumen, puesto que el cardumen es vida y atrae un sinnúmero de otra fauna que se alimentan de ellos, como los pájaros ya mencionados, y otros peces más grandes como albacoras, delfines y otros.

El jurel y la sardina se movilizarían en cardúmenes acercándose en algunas ocasiones hacia la orilla e incluso hasta los bordes litorales. De este modo, se disponen a ir a la pesca de dicho banco de peces solo guiados por estas "pajaradas". Al llegar allí, los pescadores utilizan redes para sacar los jureles, puesto que al haber tanta abundancia sería un desperdicio estar usando línea y anzuelo; se remiten a capturar dichos peces con redes que arrojan al mar, para luego realizar una vuelta en círculo con el bote para encerrar a los jureles y recoger la red (Rubio 2012).

A mayor abundamiento, la literatura arqueológica ha señalado que es común encontrar cardúmenes de Trachurus symmetricus junto con Sardinops sagax musica, entre otros, dado que el segundo es parte de la dieta del jurel (Vargas et al. 1993) Por otra parte, en la costa del Norte Grande existen registros de la abundancia de jurel, de acuerdo a la descripción realizada por Capdeville en Taltal, donde hace referencia a la gran cantidad de esta especie en la playa persiguiendo peces para alimentarse. Estos eventos ocurren cíclicamente y responden a una serie de complejos desplazamientos en el que se desarrolla su ciclo de vida y que alcanzaría hasta Nueva Zelandia (Gerlotto et al. 2012; Reyes y Hüne 2012). El regreso hacia la costa chilena sería principalmente para alimentarse (Gerlotto et al. 2012) y es la ocasión donde las personas aprovecharían de capturarlo frente a su abundancia y fácil acceso.

Bajo un punto de vista interpretativo, podríamos argumentar que la presencia mayoritaria de jurel en el registro ictiológico de Copaca 1, se debiese a un conocimiento sobre la llegada de los cardúmenes de jureles desde aguas pelágicas hacia zonas más cercanas a la costa, en donde sus habitantes anunciados por las llamadas "pajaradas", saldrían en sus embarcaciones en busca de tan preciado y abundante recurso. En este contexto, no podemos por supuesto descartar la captura de dicho pez bajo la técnica de línea y anzuelo desde la orilla, pero pensamos que este método sería mucho menos efectivo y solo dependiente de un acercamiento significativo de los cardúmenes hacia la rompiente litoral o a aguas intermareales, en donde si bien ha sido documentada dicha situación (Patricio Núñez, comunicación personal 2010) suele ser muy esporádica. Asimismo, la notoria presencia de sardinas (Sardinops sagax sagax) en el registro ecofactual del yacimiento, se puede asociar a que dicho pez y el jurel dependen uno de otro para su alimentación, por lo que no sería raro obtener sardinas, si se está yendo en búsqueda del jurel ${ }^{10}$. Es más, ambos tipos de peces caerían en las redes en una sola maniobra.

También desde la etnografía hay una referencia al uso de la "potera", un instrumento utilizado 
actualmente para la pesca de orilla en playas arenosas y denominado "pulpo" como nos cuenta Don José Flores. Dicho artefacto es utilizado actualmente bajo la forma de un gran anzuelo de cuatro puntas, cual arrojan desde la orilla hacia la rompiente arenosa lo más adentro que puedan, y luego comienzan a recogerlo esperando "pinchar" y capturar al lenguado que se arrastra bajo el lecho arenoso. Cabe destacar que no es solo utilizado para la captura del lenguado pues el objetivo de este instrumento es pinchar y pillar cualquier recurso que se cruce en su camino, pero suele ser vinculado normalmente con la captura del lenguado, la corvina y la corvinilla. En este ámbito, el hallazgo de cuatro pequeños punzones asociados a los individuos bajo entierro secundario del sitio en estudio, podrían quizás corresponder a las cuatro puntas de una de estas poteras (Rubio 2012). Según Silva y Bahamondes (1968) su función sería la captura de cefalópodos, es decir, calamares y jibias. Según los antecedentes aportados por estos autores, este instrumento debe ser lanzado hasta el fondo marino para luego ser recogido y con este gesto, provocar movimientos verticales y el brillo de las barbas, para de esta manera, llamar la atención de las presas. De ahí que los autores concluyen que el instrumento debió ser usado desde una embarcación.

\section{Acerca de la utilización de peces y mamíferos marinos}

Los peces residentes de ambiente litoral rocoso dominan el conjunto de Copaca 1, sugiriendo un tipo de pesca mayoritariamente de orilla. Las excavaciones confirman la estacionalidad de esta especie-jureles-pues hay capas en que está ausente, contrastando con la gran abundancia que presenta en otras. La presencia mayoritaria de esta especie en Copaca 1, es similar a la que se encuentra en otros sitios de esta área, como en Guasilla (70\%) y en sitios tardíos, como en Cobija $1 \mathrm{~N}$ y 24 , donde llega a un $78 \%$. Excepcionalmente en el sitio arcaico de Mantos de la Luna, donde la diversidad taxonómica es menos variada, la representación de jurel desciende a 30\%, siendo reemplazado por bilagay (Cheilodactus variegatus), rollizo (Pinguipes chilensis) y tomollo (Auqueniochus microcirrhis). Esto significa que el jurel fue probablemente la más abundante fuente de alimentación en la zona por espacio de 5.000 años. De hecho, en Copaca, la mayoría de las marcas de exposición de huesos al fuego, son de esta especie. Aunque no se han encontrado testimonios arqueológicos que lo avalen, es posible que se haya capturado con redes, especialmente cuando se presenta en cardúmenes.

La presencia de peces oceánicos, como ya hemos observado, trae a la palestra la posible existencia de embarcaciones durante el Arcaico Medio en el área de estudio ${ }^{11}$.

La subclase Elasmobranquio, llega a 14,3\% en la capa 1 y en las capas 2 y 3 a $4 \%$, también puede indicar acceso a mar afuera. En Guasilla 2 esta subclase, que comprende las especies sierra, raya y tiburón, es especialmente abundante en la unidad 4 , donde alcanza a $95 \%$ en la capa 9 y $30,55 \%$ en la capa 12, ambas fechadas en momentos anteriores al 5.000 a.p. Para estudiar esta importante presencia como indicador de navegación, habría que saber de qué especies se trata y la edad de los ejemplares, pues es común que los juveniles se acerquen a la costa.

Es abundante la presencia de sardina, en capas 3 y 4 alcanza a un 50,9\% y un $56 \%$, respectivamente, sin embargo se debe hacer notar que los restos mayoritarios de esta especie son de vértebras, lo que haría reducir en NMI. También los restos encontrados pueden ser parte de contenidos estomacales de peces ictiófagos, especialmente el jurel y bonito. Estas tres especies forman parte de una característica cadena trófica marina.

De acuerdo con el análisis de la oseofauna de este sitio, existe abundante presencia de restos óseos correspondientes a la familia Delphinidae, evidenciada principalmente en vértebras, fragmentos de cráneo (mandíbulas, frontales y occipitales) y perióticos. Dichos restos se han registrado principalmente en las capas superiores de la excavación, como también asociadas al contexto de inhumación en las capas 5 y 6 . Esto podría implicar que el asentamiento constituyó un área de descarte primaria y secundaria de estas presas, comportamiento típico de un campamento residencial semipermanente del Arcaico costero del norte de Chile. Otros taxa identificados hasta el momento destacan la presencia de mamíferos marinos como Otariidae y Cetácea.

En lo que se refiere al concepto pueblos con capacidad de "navegación", pensamos que este término incluye un sinnúmero de variables que son indudablemente muy difíciles de comprobar, puesto que el hecho de "navegar" incluye el desplazamiento a través de largas distancias, uso de velamen, confección de embarcaciones con quillas 
para poder desplazarse linealmente y no quedar sujeto a la corriente de deriva, etc.

En este marco, es posible que las poblaciones que nos encontramos estudiando hayan poseído capacidades de construcción de balsas que les permitieran acercarse al segmento batitudinal marino, para poder acceder a recursos ictiológicos de orden pelágico y migratorio, y para el caso de los recursos malacológicos, para poder alcanzar bajerías poseedoras de especímenes de mayor biomasa y tamaño, puesto que como es esperable, los especímenes ubicados en bajas profundidades, pudieron tender a ser más pequeños y los que pudiesen tener mayor tamaño, haber sido extraídos ya con anterioridad.

En definitiva, para poder realizar la caza con arpones o pesca de especímenes como bonito, albacora, escualos y congrios, pensamos que se debió poseer alguna tecnología de adentramiento al mar, con un notable grado de estabilidad, ya sea esta denominada embarcación o balsa, lo preponderante es que dicha invención les permitió capturar fauna marina que requiere de un sistema de flotación estable para poder "trabajar" a la presa, hasta cansarla y poder subirla a la embarcación; poseer tecnologías de pesca y caza, posibles de capturar especímenes de gran tamaño como los mencionados anteriormente y un conocimiento de las corrientes y geomorfología de la costa para poder entrar y salir de la línea de rompiente sin problemas.

En definitiva, en el conjunto íctico de Copaca 1 los restos de peces oceánicos es reducido y una posibilidad de abordar el tema sería considerarlas como un ítem de prestigio. Los individuos de Copaca 1 optaron por un gran número de peces de tamaños medianos y escasos individuos de grandes dimensiones como Istiophoridae y Xiphias gladius. En estas especies la agresividad y el desplazamiento de individuos solos implica una mayor energía invertida en su captura, pero el importante aporte de biomasa lo vuelve un recurso atractivo. Usualmente la dieta se basa en recursos predecibles, de rendimiento moderado pero que no implican riesgos en su obtención, como puede ser la recolección de moluscos, tarea posiblemente realizada hasta por niños y ancianos. Lo anterior concuerda con el registro faunístico de Copaca 1 , ya que la subsistencia se basó principalmente en recursos estables con cierta predictibilidad, mientras que los restos de peces oceánicos son reducidos. La captura de grandes especies implica un alto costo energético, una planificación particular, pocos individuos por evento de captura y riesgos para las personas involucradas en la labor. En consecuencia, creemos que la caza de especies grandes y agresivas pudo traducirse en prestigio para los cazadores posiblemente especializados (Reitz y Wing 2008). Estas ideas son coherentes con lo propuesto en relación a la captura de especies oceánicas y la valoración social de dicha actividad, la que además se llevaría a cabo gracias al uso de embarcaciones, al menos desde el Arcaico Medio (Olguín et al. 2014; 2015). Es así que las estrategias sobre la obtención de recursos parecen combinar un aspecto biológico y otro cultural, los que deben mantenerse en equilibrio para que un grupo pueda ser viable, ya que es imprescindible contar con un adecuado nivel nutricional para la mantención y reproducción de una población.

\section{Acerca del registro de invertebrados marinos}

En la capa 9 del sitio, se encuentran los ejemplares de Concholepas concholepas de mayor tamaño, mientras que en la capa 8 se registró la más alta cantidad en la columna de fauna de esta especie. Con respecto a la extracción de estos moluscos, se hace notar que en el registro, el tamaño decrece paulatina e invariablemente desde las capas más antiguas a las más recientes. Ello podría invitar a especular la práctica temprana del buceo, ya que la etología de estas especies indica que ellas migran hacia mayores profundidades a medida que crecen en tamaño (Castelleti et al. 2004). Sin embargo, con una práctica habitual del buceo, se podrían también haber seleccionado especies de mejor tamaño en las ocupaciones más recientes del sitio. Viejos buceadores de la costa arreica, han señalado que la ocurrencia de especies de gran tamaño eran frecuentes en roqueríos bastante cercanos a línea de playa a mediados del siglo XX y que aquellas hoy solo se encuentran en grandes profundidades.

Una explicación alternativa estaría dada por diferencias ambientales. Los depósitos de la capa 9 ocurren en un momento en que la surgencia costera y productividad primaria estarían intensificadas (Carré et al. 2005; Mohtadi et al. 2004; Ortlieb et al. 2011), lo cual implica mejores condiciones para los recursos marinos costeros. Una tercera alternativa estaría dada por un menor número poblacional de habitantes en la costa (Marquet 
et al. 2012), durante la capa 9 respecto a las más recientes (capa 8 en adelante), lo que pudo generar una mayor presión de colecta sobre el recurso marino en tiempos más tardíos, es decir una mayor colecta de ejemplares de Concholepas concholepas en este caso que aún no han alcanzado tallas grandes, lo que explicaría una disminución en su tamaño.

En relación a los diferentes tamaños y formas de acercamiento al recurso (Concholepas concholepas), está determinado por los bajos rocosos insertos dentro de las pampas arenosas submarinas, que albergan sin duda la mayor parte de la flora y fauna marina en este litoral. Aquí los buzos y pescadores actuales obtienen la mayor parte de su sustento alimenticio, y parecen conocer a la perfección la ubicación y conformación de cada una de estas bajerías, utilizándolas variablemente según las distintas condiciones del mar y de estacionalidad.

La gran importancia que poseen las llamadas "bajerías", que son conformadas por bajos rocosos que concentran la flora y fauna submarina a lo largo de este litoral. Estos refugios bióticos, son promontorios rocosos de diferentes tamaños insertos en el fondo marino, los que suelen llegar incluso hasta la superficie.

Realmente llama la atención, cómo actualmente sus pobladores describen los relieves y propiedades de los bajos rocosos sumergidos frente a la caleta en estudio, conociendo su perfecta ubicación, dirección y profundidad (Rubio 2012). Así también, las distintas formas de vida que habitan en cada una de estas "bajerías", en donde cada una manifiesta una particularidad. Debemos destacar que cada especie tiene un lugar específico donde los buzos se dirigen para su extracción. Más aún muchos se especializan solamente en una determinada especie, es decir algunos se dedican solamente a la extracción de locos, otros de lapas y algunos de choros y cholgas.

$\mathrm{El}$ acercamiento Concholepas concholepas se daría solo en ciertos hitos del paisaje submarino, como las bajerías anteriormente descritas. Asimismo, nos cuenta Don José que para buscar locos de mayor tamaño, debemos ir más profundo en busca de estos, puesto que el loco a medida que crece se va acercando siempre a aguas más profundas y más frías (Rubio 2012).

En este mismo sentido, pensamos que la abundancia de restos ecofactuales de grandes tallas para las capas 8 y 9 se podría deber a una especialización en la obtención de dichos recursos por los habitantes del lugar para este segmento temporal o a la llegada al lugar de grupos humanos con una especialización en la obtención de tales moluscos en este segmento temporal y/o a un aumento en la abundancia de tales recursos litorales frente al yacimiento en estudio durante esta fracción temporal y su consecuente aprovechamiento por las poblaciones presentes en el lugar o a la conjugación de algunos de estos elementos recién mencionados.

Los recursos preferentemente consumidos por los ocupantes de Copaca son tanto gastrópodos como fisurélidos y Tegula atra la que, a pesar de no presentar una gran biomasa, fue altamente seleccionada. Así, los invertebrados marinos se presentan como un recurso estable y constante, de fácil acceso que proporcionó la base de la dieta de las poblaciones, sin mayores variaciones a través del tiempo.

Estos invertebrados no solo tuvieron un rol en la subsistencia humana, sino también como materia prima para elaborar artefactos formatizados y expeditivos. En este sentido, se destaca el uso del Choromitylus chorus para fabricar anzuelos, en sus distintas fases de elaboración y cuchillos. Otras conchas fueron utilizadas para confeccionar cuentas de collar. Durante el Arcaico se destaca un consumo constante y mayoritario de Tegula atra y de fisurélidas por sobre los gasterópodos.

\section{Acerca de las aves}

Aunque no constituyó un principal aporte nutricional, el registro de aves identificado resulta interesante en términos económicos y de subsistencia para los grupos humanos que habitaron el sitio a lo largo del Holoceno Medio, y se ha propuesto una metodología para su estudio (Peña-Villalobos et al. 2013). Es probable que estas aves hayan nidificado en zonas accesibles para los grupos de cazadores, en colonias ubicadas en el borde costero, permitiendo diversas técnicas tradicionales de caza, que abarcarían desde el uso de lazos y redes (Gusinde 1951), hasta el empleo de lanzas con puntas de proyectil líticas, considerando que el conjunto ergológico del sitio Copaca 1 está compuesto por puntas pedunculadas y lanceoladas. También es posible el uso de hondas pues en el sitio es notable la presencia de guijarros 
de diferentes tamaños. A pesar de la ausencia en el registro de aves juveniles y huevos, no se descarta su aprovechamiento. Para concluir, el hallazgo de restos óseos de aves con evidencia de procesamiento y marcas culturales, apoyan el aprovechamiento de estas especies.

\section{Acerca de la industria lítica y artefactos formatizados}

El conjunto instrumental remitió fundamentalmente, tanto en términos morfológicos como funcionales, a actividades probablemente relacionadas con el procesamiento de mamíferos obtenidos en el contexto de prácticas de cacería. En síntesis, los grupos que ocuparon Copaca 1 utilizaron frecuentemente instrumentos líticos de bordes filosos para procesar animales cazados, evidenciándose una fuerte relación con microhuellas de corte $(38,8 \% ; \mathrm{N}=112)$. Muchos de estos bordes además fueron utilizados para raspar $(28,6 \% ; \mathrm{N}=32)$. Las microhuellas de corte fueron identificadas en doce tipos morfológicos de instrumentos, tanto en andesita como en sílice, resultando el chopper la herramienta cortante más frecuente $(18,2 \%$; $\mathrm{N}=14$ ), así como el tipo más usado para cortar y raspar $(31,2 \% ; \mathrm{N}=10)$. En términos estratigráficos, la distribución de bordes activos con microhuellas de corte sugirió que las mayores intensidades en las prácticas de faenamiento de presas ocurrieron en las ocupaciones superiores (capas 2, 3 y 4), incorporándose crecientemente bifaces además de choppers en estas tareas. Las microhuellas exclusivas de raspado representaron solamente el $4,1 \%$ de las acciones inferidas en Copaca 1 , lo que señala la importancia de los bordes usados para acciones múltiples, resultando choppers y raspadores los instrumentos más usados para raspar (33,3\%; $\mathrm{N}=4$ y $16,6 \% ; \mathrm{N}=2$, respectivamente). De igual modo, un importante conjunto de guijarros de andesita fue utilizado en acciones de abrasión, representando el $32 \%$ de las acciones inferidas $(\mathrm{N}=92)$. Los sobadores activos (Aschero 1983) destacaron en términos de frecuencia $(95,7 \%$; $\mathrm{N}=88$ ), encontrándose probablemente asociados con una importante actividad de preparación de cueros de mamíferos destinados a la confección de viviendas y vestimentas, especialmente durante las ocupaciones que conformaron las capas 3 y 4 . Los artefactos formatizados registrados en el sitio corresponden básicamente a los requeridos para explotar los recursos marinos, e incluyó anzuelos (Choromitylus) con vástago recto, pesas, barbas y poteras, instrumento mariscador, puntas de proyectil y objetos ornamentales como cuentas de concha y espátulas y cucharillas de hueso.

Para la fabricación de los instrumentos óseos se escogieron huesos de camélidos, aunque estos mamíferos solo representan 3\% dentro del registro óseo. También se usaron huesos de aves y mamíferos marinos, principalmente otáridos. En esta costa desértica la industria en hueso tomó gran importancia promovida, en gran medida, por la falta de maderas, que en otras partes más favorecidas se usó fecundamente para estos efectos.

\section{Conclusión}

Se concluye señalando que el sitio Copaca 1 es un asentamiento de carácter residencial y funerario ocupado durante más de dos mil años. Este sitio aporta al conocimiento del lapso entre el $9.000 \mathrm{y}$ 6.000 a.p., que anteriormente estaba desprovisto de registro arqueológico (Llagostera 2005:128). También proporciona evidencias novedosas acerca del modo de vida de las poblaciones costeras del litoral arreico de Antofagasta. Copaca 1 es un clásico ejemplo de la excelente adaptación marítima de estas sociedades durante el Arcaico, con un aprovechamiento integral y óptimo de los recursos marinos, entre los que predomina el jurel y caracoles marinos. La presencia de especies de mar abierto avalaría, junto a otros antecedentes, la hipótesis de navegación temprana. El único recurso terrestre registrado es el camélido, cuyos huesos largos fueron preferidos para la confección de artefactos de pesca. Ha sido providencial el hecho de encontrar un sitio intocado con tanta información en una zona altamente disturbada.

Agradecimientos: Fernanda Falabella por compartir sus conocimientos sobre isótopos estables. A FONDECYT 1100951, proyecto que financió nuestros estudios y al equipo que nos acompañó estos años; y al PROYECTO CONICYT/PIA SOC1405. A don José Flores, experto local por sus enseñanzas y hospitalidad. A los evaluadores anónimos del presente artículo por sus valiosas sugerencias, que nos han permitido incorporar registros etnográficos de gran valor. 


\section{Referencias Citadas}

Andrade, P., V. Castro y C. Aldunate 2016. Reconstrucción del modo de vida de individuos del arcaico de la costa arreica del norte de chile: una aproximación bioarqueológica desde el sitio Copaca 1. Chungara Revista de Antropología Chilena 48:73-90.

Ambrose, S. y N. Sikes 1991. Soil carbon isotope evidence for Holocene habitat change in the Kenya Rift Valley. Science 253:1402-1405.

Aschero, C. 1983 [1974]. Ensayo para una clasificación morfológica de artefactos líticos aplicada a estudios tipológicos comparativos. Informe inédito CONICET. Manuscrito en poder de los autores.

Aufderheide, A. y M. Kelley 1994. Contributions of chemical dietary reconstruction to the assessment of adaptation by ancient Highland immigrants (Alto Ramirez) to coastal conditions at Pisagua; North Chile. Journal archaeological Science 21:515-524.

Behrensmeyer, A. 1978. Taphonomic and ecologic information from bone wethering. Paleobiology 2:150-162.

Barberena, R. 2002. Los Límites del Mar: Isótopos Estables en Patagonia Meridional. Sociedad Argentina de Antropología, Colección Tesis de Licenciatura, Buenos Aires.

Berdichewsky, B. 1965. Exploración arqueológica en la costa de la provincia de Antofagasta. Publicación del Centro de Estudios Antropológicos: 3-30, Universidad de Chile, Santiago.

Berenguer, J. 2009. Las pinturas de El Médano, norte de Chile: 25 años después de Mostny y Niemeyer. Boletín del Museo Chileno de Arte Precolombino 14:57-95.

Bittmann, B. 1984. El proyecto Cobija: investigaciones antropológicas en la costa del desierto de Atacama (Chile). Actas del XLIV Congreso Internacional de Americanistas, 1982, pp. 99-146. Universidad del Norte, Antofagasta.

Bobst, A.L., T.K. Lowenstein, T.E. Jordan, L.V. Godfrey, T.L. $\mathrm{Ku}$ y S. Luo 2001. A 106 ka paleoclimate record from drill core of the Salar the Atacama, northern Chile. Paleogeography, Paleoclimatology, Paleoecology 173:21-42.

Bovy, K. 2002. Differential avian skeletal part distribution: explaining the abundance of wings. Journal of Archaeological Science 29:965-978.

Bovy, M. 2012. Why so many wings? A re-examination of avian skeletal par representation in the south-central Northwest Coast, USA. Journal of Archaeological Science 39:2049-2059.

Capdeville, A. 1921. Capdeville, Notas acerca de la arqueología de Taltal. I. VOL II. Num 3-4: 1-16. Tipografía y Encuadernación Salesianas, Quito.

Carré, M., I. Bentaleb, M. Fontugne y D. Lavallée 2005. Strong El Niño events during the early Holocene: stable isotope evidence from Peruvian seashells. The Holocene 15:42-47.

Castelleti, J., O. Reyes, G. Maltrain, I. Martínez, P. Galarce, H. Velásquez y J.P. Ugalde 2010. Ocupaciones en abrigos rocosos en la costa de Taltal: Patrón de uso del espacio desde momentos holocénicos tempranos. Actas del XVII Congreso Nacional de Arqueología Chilena, Valdivia 2006, Vol. 2, pp. 685-695.

Castelleti J., O. Reyes, H. Velázquez, I. Martínez, V. Trejo, D. Baudet, P. Galarce, G. Maltrain, C. Belmar, L. Quiroz, M. De la Maza y J.P. Ogalde 2004. Rescate de los sitios arqueológicos 226-5 y 228/230 INFORME FINAL. Construcción y mejoramiento Ruta-1 Taltal-Paposo. Convenio CMT-MOP, Consejo Monumentos Nacionales, Chile.

Castillo, K., C. Ibáñez, C. González y J. Chong 2007. Dieta del pez espada Xiphias gladius Linnaeus, 1758 en distintas zonas de pesca frente a Chile central durante el otoño de 2004. Revista de Biología Marina y Oceanografía 42:149-156.

Cocilovo, J., H. Varela, M.A. Costa-Junqueira y S. Quevedo 2005. Los pescadores arcaicos de la desembocadura del río Loa (norte de Chile): El sitio Caleta Huelén 42. Chungara Revista de Antropología Chilena 37:5-19.

Contreras, R. y P. Núñez 2008. Los Bronces-1: Un asentamiento de 5.500 años en la costa de Taltal. Taltalia 1:61-74.

Contreras, R., P. Núñez, A. Llagostera, J. Cruz, A. San Francisco, B. Ballester, O. Rodríguez y G. Becerra 2011. Un conglomerado del período arcaico costero medio del área Taltal Paposo, Norte de Chile. Taltalia 4:7-31.

Chong, J. y M. Aguayo 2009. Edad y crecimiento del pez espada (Xiphias gladius Linnaeus, 1758) en el Pacífico suroriental (Diciembre 1994-Septiembre 1996). Latin American Journal of Aquatic Research 37:1-15.

Falabella, F., M.T. Planella, E. Aspillaga, L. Sanhueza y R. Tykot 2007. Dieta en sociedades alfareras de Chile central: aporte de análisis de isótopos estables. Chungara Revista de Antropología Chilena 39:5-27.

García Albarido, F. 2012. Estrategias de Subsistencia en Cobija durante el Periodo Intermedio Tardío y el Tawantinsuyu. Aproximación desde la Funcionalidad de los Instrumentos Líticos. Memoria para optar al título de Arqueólogo. Facultad de Ciencias Sociales, Universidad de Chile, Santiago.

Gerloto F., M. Gutiérrez y A. Bertrand 2012. Insight on population structure of the Chilean Jack macherel (Trachurus murphyi). Aquatic Living Resources 25:341-355.

Grosjean, M., I. Cartajena, M.A. Geyh y L. Núñez 2003. From proxy data to paleoclimate interpretation: the mid-Holocene paradox of the Atacama Desert, northern Chile. Palaeogeography, Palaeoclimatology, Palaeoecology 194:247-258.

Grosjean, M., J.F.N. van Leeuwen, W.O. van der Knaap, M.A. Geyh, B. Ammann, W. Tanner, B. Messerli, L. Núñez, B.L. Valero-Garcés y H. Veit 2001. A 22,000 14C year BP sediment and pollen record of climate change from Laguna Miscanti $\left(23^{\circ} \mathrm{S}\right)$, northern Chile. Global and Planetary Change 28:35-51.

Gusinde, M. 1951. Fueguinos. Hombres primitivos en la Tierra del Fuego (de investigador a compañero de tribu). Escuela de Estudios Hispanoamericanos, Sevilla.

Guerra, C. y D. Torres 1987. Presence of the South American fur seal, Arctocephalusaustralis, in the Northern Chile. En Status, Biology and Ecology of Fur Seal, editado por J.P. Croxall y R.L. Gentry, pp. 169-175. Proceedings of an international symposium and workshop, Cambridge, 23-27 April 1984. 
Jurmain, R.D. y L. Kilgore 1995. Skeletal evidence of osteoarthritis: a paleopathological perspective. Annals of Rheumatoid Disease 54:443-450.

Kennedy, K.A.R. 1989. Skeletal markers of occupational stress. En Reconstruction of Life from the Skeleton, editado por M.Y. Iscan y K.A.R. Kennedy, pp. 129-160. Alan R. Liss, Inc. New York.

Llagostera, A. 1982. Tres dimensiones en la conquista prehistórica del mar: un aporte para el estudio de las formaciones pescadoras de la costa sur andina. Actas del VIII Congreso de Arqueología Chilena, pp. 217-245. Ediciones Kultrun, Santiago.

Llagostera, A. 1989. Caza y Pesca Marítima (9000 a 1000 a.C.). Prehistoria desde sus Orígenes hasta los Albores de la Conquista, editado por J. Hidalgo, V. Schiappacasse, H. Niemeyer, C. Aldunate e I. Solimano, pp. 57-79. Editorial Andrés Bello, Santiago.

Llagostera, A. 1990. La navegación prehispánica en el norte de Chile: bioindicadores e inferencias teóricas. Chungara 24-25:37-51.

Llagostera, A. 2005. Culturas costeras precolombinas en el norte chileno: secuencia y subsistencia de las poblaciones arcaicas. En Biodiversidad Marina: Valoración, Usos y Perspectivas, editado por E. Figueroa, pp.107-148. Ed. Universitaria, Santiago.

Letelier, S., R. Meléndez, E. Carreño, S. López y P. Barría 2009. Alimentación y relaciones tróficas del pez espada (Xiphias gladius Linnaeus, 1758), frente a Chile centro - norte durante 2005. Latin American Journal of Aquatic Research 37:107-119.

Loyola, A. y M. Rebeco 2001. Bioarqueología de la Infancia y Marcadores Ocupacionales en la Costa Arreica Central en el Norte de Chile. Memoria para optar al título de Antropólogo, Universidad de Concepción, Concepción.

Lyman, R.L. 1994. Vertebrate Taphonomy. Cambridge Manuals in Archaeology. University Press, Cambridge.

Marquet, P.A., C.M. Santoro, C. Latorre, V.G. Standen, S.R. Abades, M.M. Rivadeneira, B. Arriaza y M.E. Hochberg 2012. Emergence of social complexity among coastal hunter-gatherers in the Atacama Desert of northern Chile. Proceedings of the National Academy of Sciences of the United States of America 109:14754-14760

Molnar, P. 2006. Tracing prehistoric activities: musculoskeletal stress marker analysis of a Stone-Age population on the Island of Gotland in the Baltic Sea. American Journal of Physical Anthropology 12912-23.

Mostny, G. y H. Niemeyer 1983. Arte Rupestre Chileno. Serie el patrimonio cultural chileno. Colección Historia del Arte Chileno, Santiago.

Mohtadi, M., O.E. Romero y D. Hebbeln 2004. Changing marine productivity off northern Chile during the past 19 000 years: a multivariable approach. Journal of Quaternary Science 19:347-360.

Moy, C.M., G.O. Seltzer, D.T. Rodbell y D.M. Anderson 2002. Variability of El Niño/Southern Oscillation activity at millennial timescales during the Holocene epoch. Nature 420:162-165.
Núñez, L. 1971. Secuencia y cambio en los asentamientos humanos de la desembocadura del río Loa en el norte de Chile. Boletín de la Universidad de Chile 112:3-25.

Núñez, L. 1983. Paleoindio y Arcaico en Chile: Diversidad, Secuencia y Proceso. Escuela Nacional de Antropología. Editorial Cuicuilco, México, D.F.

Núñez, L. 1989. Hacia la producción de alimentos y la vida sedentaria (5000 a. C. a 900 d.C.). En Culturas de Chile. Prehistoria. Desde sus Orígenes hasta los Albores de la Conquista, editado por J. Hidalgo, V. Schiappacasse, H. Niemeyer, C. Aldunate e I. Solimano, pp. 81-106. Ed. Andrés Bello, Santiago.

Núñez, L., P. de Souza, I. Cartajena y C. Carrasco 2008. Quebrada Tulan: Evidencias de interacción circumpuneña durante el Formativo Temprano en el sureste de la cuenca de Atacama. Producción y circulación prehispánicas de bienes en el sur andino. En Colección Historia social Precolombina, editado por A. Nielsen, M. Clara Rivolta, V. Seldes, M.M. Vásquez y P. Mercolli, Vol. 2, pp. 287-304. Ed. Brujas, Córdoba.

Núñez, L., V. Zlatar y P. Núñez 1974. Caleta Huelén 42 una aldea temprana en el Norte de Chile. (Nota preliminar). Revista Hombre y Cultura. Tomo II (5):67-103. Centro de Investigaciones Antropológicas, Universidad de Panamá, ciudad de Panamá

Núñez, P. 2003. Vivir el Mar. Ed. Universidad de Antofagasta, Antofagasta.

Núñez, P. y R. Contreras 2009. A propósito de una miniatura de balsa en Taltal contemporánea con Chinchorro. Taltalia 2:98-110.

Olguín, L. 2011. Historia de un Conchal: Procesos de Formación y Secuencia Ocupacional del Sitio Arqueológico Agua Dulce, Costa Arreica del Desierto de Atacama, Comuna de Taltal, Región de Antofagasta. Memoria para optar al Título de Arqueóloga. Universidad de Chile, Santiago.

Olguín, L., V. Castro, P. Castro, I. Peña-Villalobos, J. Ruz y B. Santander 2015. Exploitation of journal resources by marine hunter-gatherer groups during the Middle Holocene at the Copaca 1 site, Atacama Desert coast. Quaternary International 373:4-16.

Olguín, L., D. Salazar y D. Jackson 2014. Tempranas evidencias de navegación y caza de especies oceánicas en la costa pacífica de Sudamérica (Taltal 7.000 años cal. a.p.). Chungara Revista de Antropología Chilena 46:177-192.

Orquera, L. y E.L. Piana 1986. Normas para la Descripción de Objetos Arqueológicos de Piedra Tallada, pp. 3-66. CADIC, Buenos Aires.

Ortlieb, L., G. Vargas, y J.F. Saliège 2011. Marine radiocarbon reservoir effect along the northern Chile-southern Peru coast (14-24 $\left.{ }^{\circ} \mathrm{S}\right)$ throughout the Holocene. Quaternary Research 75:91-103.

Peña-Villalobos, I., L. Olguín, P. Fibia, V. Castro y M. Sallaberry 2013. Aprovechamiento humano de aves marinas durante el Holoceno medio en el litoral árido del norte de Chile. Revista Chilena de Historia Natural 86:301-313.

Quintana, V., J. Yánez y M. Valdevenito 2000. Orden carnívora. En Mamíferos de Chile, editado por A. Muñoz-Pedreros y J. Yánez, pp. 155-188. CEA Ediciones, Valdivia. 
Pueyo, S., C. Viseras, J.M. Soria, J.E. Tent Manclus y A. Arribas 2011. A stratigraphic framework for the Pliocene-Pleistocene continental sediment of the Guadix Basin (Betic Cordillera, s. Spain). Quaternary International 243:16-32.

Rein, B., A. Lückge, L. Reinhardt, F. Sirocko, A. Wolf y W.C. Dullo 2005. El Niño variability off Peru during the last 20,000 years. Paleoceanography 20: PA 4003.

Riedinger, M.A., M. Steinitz-Kannan, W.M. Last y M. Brenner 2002. A $610014 \mathrm{C}$ yr record of El Niño activity from the Galápagos Islands. Journal of Paleolimnology 27:1-7.

Reinhard, K. y O. Urban 2003. Diagnosing ancient diphyllobothriasis from Chinchorro mummies. Memórias do Instituto Oswaldo Cruz 98:191-193.

Reitz, F. y E. Wing 2008. Zooarchaeology. Cambridge Manual in Archaeology. Cambridge University Press, Cambridge.

Reyes, P. y M. Hüne 2012. Peces del Sur de Chile. Ocho libros Editores, Santiago.

Rubio, F. 2012. Hermanos del Mar. Estudio del Sitio Arcaico Copaca 1. Una Aproximación Etnoarqueológica. Tesis para optar a título profesional de arqueólogo. Universidad Internacional SEK, Santiago.

Salazar, D., V. Castro, J. Michelow, H. Salinas, V. Figueroa y B. Mille 2010. Minería y metalurgia en la costa arreica de la región de Antofagasta, Norte de Chile. Boletín del Museo de Arte Precolombino 15:9-23.

Salazar, D., V. Castro, H. Salinas y V. Varela 2009. Nuevas investigaciones sobre la prehistoria y la antigua minería de Taltal. Taltalia 2:111-118.

Santander, B. 2010. Informe de análisis de artefactos óseos del sitio Copaca I. FONDECYT 1100951. Manuscrito en poder de los autores.

Schaedel, R. 1957. Informe general sobre la expedición a la zona comprendida entre Arica y La Serena. En Arqueología Chilena, Contribución al Estudio de la Región Comprendida entre Arica y La Serena, editado por R.P. Schaedel, pp. 1-42. Universidad de Santiago, Santiago.

Sielfeld, W., C. Guerra, R. Durán, E. Acuña, A. Aguayo-Lobo, M. Sepúlveda, F. Palma, A. Malinarich, G. Cerda, A. Bolvaran, R. Grau, X. Veloso, Y. Guerra, M. Vargas, N. Amado, R. Peredo y J. Galaz 1997. Monitoreo de la pesquería y censo del lobo marino común en el litoral de la I - IV Regiones. Informe Final Proyecto Fondo de Investigación Pesquera 95 - 28, Subsecretaría de Pesca, Valparaíso.

Silva, F. y R. Bahamondes 1978. La Potera, anzuelo para cefalópodos. Anales del Museo de Historia Natural de Valparaíso 1:217-237.

Standen, V., B. Arriaza y C. Santoro 1995. Una hipótesis ambiental para un marcador óseo: la exostosis auditiva externa en las poblaciones humanas prehistóricas del desierto del norte de Chile. Chungara 27:99-116.

Standen, V.G., B.T. Arriaza y C.M. Santoro 1997. External auditory exostosis in prehistoric Chilean populations: A test of the cold-water hypothesis. American Journal of Physical Anthropology 103:119-129.

Standen, V. y L. Núñez 1984. Indicadores antropológicos, físicos y culturales del cementerio precerámico Tiliviche II (Norte de Chile). Chungara 12:135-154.

Tieszen, L.L. y M. Chapman 1992. Carbon and nitrogen isotopic status of the major marine and terrestrian resources inb the Atacama Desert of Northern Chile. Proceedings of the First World Congress on Mummy Studies. Tomo 1, pp. 409-426. Museo Arqueológico y Etnográfico de Tenerife, Cabildo de Tenerife.

Tieszen, L.L., E. Iversen y S. Matzner 1992. Dietary reconstruction based on carbon, nitrogen and sulphur stables isotopes in the Atacama Desert, Northern Chile. Proceedings of the First World Congress on Mummy Studies. Tomo 1, pp. 427-441. Museo Arqueológico y Etnográfico de Tenerife, Cabildo de Tenerife.

Torres, D. 1985. Presencia del lobo fino sudamericano (Arctocephalusaustralis) en el norte de Chile, como consecuencia de El Niño 1982-83. Investigaciones Pesqueras 32:225-233.

Torres, D., C. Guerra y M. Sallaberry 1983a. El lobo fino del sur Arctocephalusaustralis en el norte de Chile. Boletín Antártico Chileno Vol. 3, Tomo 1, pp. 23-24.

Torres, D., C. Guerra y M. Sallaberry 1983b. Registros de Arctocephalusaustralis (Zimm. 1783) en Antofagasta II Región, Chile, y comentarios sobre su distribución goegráfica (Pinnipedia: Otariidae). Estudios Oceanológicos Vol. 3, Tomo 1, pp. 31-40.

Tykot, R., F. Falabella, M.T. Planella, E. Aspillaga, L. Sanhueza y C. Becker 2009. Stable isotopes and archaeology in Central Chile: Methodological problems for dietary reconstruction. Journal of Osteoarchaeology 129:156-170.

Uhle, M.1922. Fundamentos Étnicos y Arqueología de Arica y Tacna (Segunda edición). Sociedad Ecuatoriana de Estudios Históricos, Quito.

Vargas, G., L. Ortlieb y J. Rutllant 2000. Aluviones históricos en Antofagasta y su relación con eventos El Niño/Oscilación del Sur. Revista Geológica de Chile 27:157-176.

Vargas, G., J.A. Rutllant y L. Ortlieb 2006. ENSO tropicalextratropical climate teleconnections and mechanisms for Holocene debris flows along the hyperarid coast of western South America $\left(17^{\circ}-24^{\circ} \mathrm{S}\right)$. Earth and Planetary Science Letters 249:467-483.

Zlatar, V. 1983. Replanteamiento sobre el problema Caleta Huelén 42. Chungara 10:18-21. 


\section{Notas}

1 Representada por las ocupaciones iniciales de La Chimba 13 o quebrada Las Conchas (Llagostera 1979, 1989, 1993), El Obispo 1 y Los Médanos 2 (Llagostera 2005; Llagostera et al. 2000) y en la desembocadura de quebrada Cascabeles en la costa de Taltal (Castelleti et al. 2010).

2 Llagostera (2005) deduce que estamos frente a una tradición que no es experimental, sino que ya está adaptada de forma madura a la vida costera.

3 Esta fase está representada por los sitios Cobija 13, Abtao 1, Cerro Colorado y Punta Morada, en Taltal; Punta Blanca y Punta Guasilla (Llagostera 2005) entre Antofagasta y Tocopilla.

$4 \quad$ La Fase V está presente en sitios como Caleta Huelén 42 (Núñez 1971; Núñez et al. 1975; Zlatar 1983), Cobija-13 (Bittman 1984) y Los Bronces 1 en Taltal (Contreras y Núñez 2008).

5 También han aparecido estas estructuras en el sitio Los Canastos en la península de Mejillones, entre Antofagasta y Tocopilla.
6 La localidad de Copaca figura por primera vez en la literatura arqueológica en un artículo de Berdichewsky (1965).

7 Aunque la identificación de estas sustancias requiere estudios especializados.

8 Estos instrumentos también podrían ser adornos cefálicos según señala Isabel Cartajena (comunicación personal a Victoria Castro, 2012).

9 Estos anzuelos han servido como elemento diagnóstico para la costa de Antofagasta en el Arcaico Medio (sub-fase tardía de la Fase IV), (Llagostera 2005).

10 Capdeville (1921) presencia en Taltal los cardúmenes de jurel que se acercaban a la playa en verano, persiguiendo a las anchoas, donde se podían capturar a mano.

11 En la capa 9 de Copaca, fechada en 9.145+-30 a.p. aparecen restos de bonito (Sarda chilensis), especie que alcanza a $7 \%$ en la capa 8 . El bonito, aunque de ambientes pelágicos no se le encuentra fácilmente en la costa, se alimenta del jurel y especímenes jóvenes suelen acercarse a la costa en su persecución. Es interesante estudiar esta cadena trófica bonito-jurel-sardina. 